\title{
ÁREAS DE VULNERABILIDADE EM NATAL/RN, BRASIL: ANÁLISE DA ZONA DE PROTEÇÃO AMBIENTAL 9 (ZPA 9)
}

\author{
Anderson Geová Maia de Brito \\ Universidade Federal do Rio Grande do Norte, Departamento de Geografia \\ andersongeova17@gmail.com \\ Lutiane Queiroz de Almeida \\ Universidade Federal do Rio Grande do Norte, Departamento de Geografia \\ lutianealmeida@hotmail.com
}

Marysol Dantas de Medeiros Universidade Federal do Ceará, Departamento de Geografia marysol.dantasd@gmail.com

Juliana Felipe Farias

Universidade Federal do Rio Grande do Norte, Departamento de Geografia julianafelipefaias@yahoo.com.brm

\begin{abstract}
RESUMO
Historicamente, grupos sociais marginalizados e economicamente vulneráveis de países emergentes e subdesenvolvidos, se instalam em áreas instáveis do ponto de vista físicoambiental, amplificando riscos já existentes ou propiciando a ocorrência de desastres. Diante desse contexto, a presente pesquisa buscou identificar e analisar as áreas de vulnerabilidade ambiental da Zona de Proteção Ambiental 9 (ZPA 9), que está localizada na Zona Administrativa Norte do município de Natal/RN. Este objetivo levou em consideração que a ZPA 9 é umas das cinco Zonas Ambientais não regulamentadas do município, o que acarreta especulação imobiliária, práticas econômicas nocivas e um avanço urbano desordenado. A partir de pesquisas bibliográficas, fundamentou-se teoricamente a pesquisa em literaturas que tratam dos conceitos de risco, perigo e vulnerabilidade na ciência Geográfica, e metodologicamente nos processos morfodinâmicos das unidades geoambientais, os quais através dos Planos de Informação (PIs), forneceram a partir de uma média simples, o Índice de Vulnerabilidade Ambiental da ZPA 9. No qual observou-se que as médias de vulnerabilidade variam de 1,6 (moderamente estável) a 3,0 (vulnerável), representadas cartograficamente pela classificação RGB de cores.
\end{abstract}

Palavras-chave: Risco. Meio ambiente. Zoneamento. Geografia Física.

\section{VULNERABILITY AREAS IN NATAL/RN, BRAZIL: ANALYSIS OF THE ENVIRONMENTAL PROTECTION AREA 9 (ZPA 9)}

\begin{abstract}
Historically, marginalized and economically vulnerable social groups from emerging and underdeveloped countries have settled in unstable areas from the physical-environmental point of view, amplifying existing risks or promoting the occurrence of disasters. Given this context, this research sought to identify and analyze the areas of environmental vulnerability of Environmental Protection Zone 9, which is located in the Northern Administrative Zone of the municipality of Natal/RN. This objective has taken into consideration that ZPA 9 is one of the five unregulated Environmental Zones of the municipality, which entails real estate speculation, harmful economic practices and a disorderly urban advance. From bibliographic researches, it was theoretically based the research in literature that deals with the concepts of risk, danger and vulnerability in Geographic science, and methodologically in the morphodynamic processes of geo-environmental units, which through the Information Plans (IPs), provided from a simple average, the Index of Environmental Vulnerability of ZPA 9. In which it was observed that the averages of vulnerability vary from 1.6 (Moderately Stable) to 3.0 (vulnerable), represented graphically and cartographically by RGB classification of colors.
\end{abstract}

Keywords: Risk. Environment. Zoning. Physical Geography.

\begin{tabular}{|c|c|}
\hline Caminhos de Geografia & Uberlândia \\
\hline
\end{tabular}


Áreas de vulnerabilidade em Natal/RN, Brasil: análise da Zona de Proteção Ambiental 9 (ZPA 9)
Anderson Geová Maia de Brito Lutiane Queiroz de Almeida Marysol Dantas de Medeiros Juliana Felipe Farias

\section{INTRODUÇÃO}

O crescimento demográfico e a expansão urbana desordenada, correspondem a uma das principais características históricas e atuais dos países emergentes e subdesenvolvidos. E no caso da cidade de Natal, capital potiguar, este fato não é diferente, pois a explosão urbano-demográfica iniciada nas últimas décadas do século XX, não só promoveram a segregação socioespacial da cidade, como também produziram, aliadas a imigração e a pobreza, a ocupação de encostas íngremes e dunas por populações que não tinham o amparo do Estado, totalizando no ano de 2007, 74 áreas de risco, segundo dados do "Plano Municipal de Redução de Risco do Município de Natal" elaborado pela Secretaria de Meio Ambiente e Urbanismo de Natal (SEMURB) em 2008 (NATAL, 2008).

Visando instaurar a política urbano-ambiental das cidades brasileiras, a Lei 10.257/2001, do Estatuto das Cidades, estabelece o Zoneamento Ambiental como um dos instrumentos de organização do espaço urbano, em seu cap. II, seção I, art. 4. E seguindo este princípio, o Plano Diretor de NatalPDN/2007 - Lei Complementar no 082, de 21 de junho de 2007 (NATAL, 2007), artigo17 - , estabelece o macrozoneamento do município, definindo três zonas a partir de sua função social e físico-ambiental diferenciadas: I - Zona de Adensamento Básico; II - Zona Adensável; III - Zona de Proteção Ambiental.

Dessa forma, segundo o que foi estabelecido no Plano Diretor Municipal da cidade do Natal (NATAL, 2007), a Zona de Proteção Ambiental (ZPA) é toda e qualquer área na qual as "características do meio físico restringem o uso e ocupação, visando a proteção, manutenção e recuperação dos aspectos ambientais, ecológicos, paisagísticos, históricos, arqueológicos, turísticos, culturais, arquitetônicos e científicos", indicando que Natal possui 10 ZPAs, consistindo então a ZPA 9 em um conjunto de ecossistemas de dunas e lagoas interdunares e fluviais, situados ao longo do Rio Doce, conforme a figura 1.

Figura 1 - Mapa de Localização da Zona de Proteção Ambiental 9 (ZPA 9).

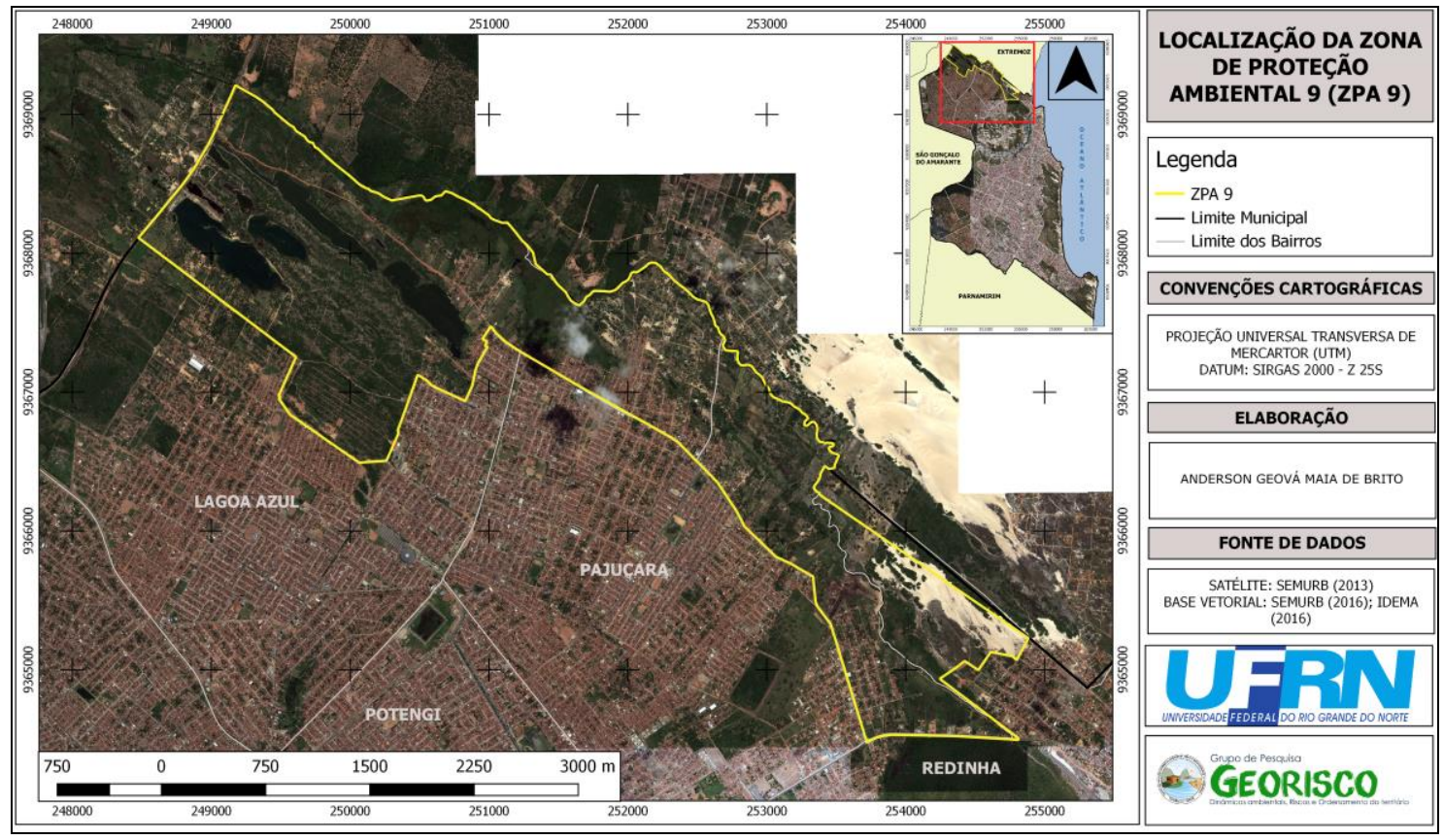

Fonte: elaboração dos autores.

A ZPA 9, entretanto, é uma zona não regulamentada, o que acarreta especulação imobiliária, práticas econômicas nocivas e um avanço urbano desordenado por meio de grupos populacionais socialmente vulneráveis. Dessa forma, esta pesquisa teve como objetivo, analisar a vulnerabilidade ambiental da ZPA 9, a partir da correlação entre as unidades geoambientais com as formas de uso e ocupação nela presentes, identificando os principais riscos e impactos socioambientais resultantes e

$\begin{array}{llllll}\text { Caminhos de Geografia } & \text { Uberlândia } & \text { v. } 20, \text { n. } 72 & \text { Dez/2019 } & \text { p. } 433-453 & \text { Página } 434\end{array}$


externando dessa forma a dicotomia entre o que está previsto nas legislações pertinentes e o que se tem concretizado.

\section{DISCUSSÃO A RESPEITO DOS CONCEITOS DE RISCO, PERIGO E VULNERABILIDADE}

Etimologicamente o termo "risco" não possui uma origem específica, entretanto ele está presente na maioria dos idiomas: risk (inglês), rischio (italiano), riesgo (espanhol), risque (francês), rhikizon (grego) ou rixare (latim). E de uma forma ou de outra, tanto em sua origem etimológica, "risico" ou "rischio", refere-se a um constructo social, ou seja, está relacionado a um perigo em potencial ou a noção de percepção dele (VEYRET, 2007).

Dessa forma, o risco segundo Esteves (2011, p. 64) pode ser entendido como "uma situação de perigo ou possibilidade de perigo", seja ela conhecida ou não, ou o risco pode designar de acordo com Veyret $(2007$, p. 25$)$ um "perigo em potencial quando sua percepção indica uma situação percebida como perigosa na qual se está ou cujos efeitos podem ser sentidos". E para efeito de síntese, o risco, "refere-se, portanto, à probabilidade de ocorrência de processos no tempo e no espaço, não constantes e não-determinados, e à maneira como estes processos afetam (direta ou indiretamente) a vida humana" (CASTRO et al., 2005, p. 12).

Tratado e abordado como categoria de análise em inúmeras ciências, o risco, conforme destaca Almeida (2012),possui uma característica marcante, que é a da multidisciplinaridade, uma vez que seu conceito está associado às noções de "incerteza, exposição ao perigo, perda e prejuízos materiais, econômicos e humano sem função de processos de ordem 'natural' (tais como processos exógenos e endógenos da Terra) e/ou daqueles associados ao trabalho e as relações humanas" (CASTRO et al., 2005, p. 12).

Além de ser uma categoria de análise multidisciplinar, o risco possui adjetivos que o qualificam segundo o grau de exposição de uma sociedade a um perigo em potencial, tendo-se, portanto, o risco ambiental, social, biológico e entre outros. Dessa forma, há três principais abordagens: a primeira, com enfoque em processos catastróficos e rápidos, sob a responsabilidade das geociências; uma abordagem que trata das questões empresariais e financeiras, e por último, a abordagem geográfica, que trata dos chamados riscos ambientais, tecnológicos e sociais (ALMEIDA, 2012; CASTRO et al., 2005).

A exposição a estes riscos torna as populações contemporâneas, sujeitas ao perigo, onde vale salientar que estes dois termos não são sinônimos. Segundo Smith (2001), o perigo é "uma ameaça potencial para as pessoas e seus bens, enquanto risco é a probabilidade da ocorrência de um perigo e de gerar perdas", sendo assim o perigo, um componente do risco, uma vez que ele, "não inclui obrigatoriamente a quantificação e/ou qualificação de prejuízos para a sociedade" (CASTRO et al., 2005, p. 17).

Segundo Giddens (1991), a diferença entre os termos risco e perigo está na consciência ou na inconsciência do quão o indivíduo ou os indivíduos estão se arriscando, pois o que risco pressupõe é o perigo e não a tomada de consciência deste, pois cada um assume consciência da ameaça ou da provável ameaçada, "mas é certamente possível assumir ações ou estar sujeito a situações que são inerentemente arriscadas sem que os indivíduos envolvidos estejam conscientes do quanto estão se arriscando" (GIDDENS, 1991, p. 36).

Tanto o risco quanto o perigo, estão contidos nos estudos sobre hazards, mais precisamente nos de natural harzard, que é o grande foco dos geógrafos. O hazard, segundo White (2001), é um evento não natural que ocorre na interface da sociedade-natureza, em que há danos e prejuízos a partir de um evento, constantemente extremo e não tão raro, que rompe com um ciclo natural de ocorrência de fenômenos naturais, como terremotos e/ou furacões.

Com base em Jones (1993), Marandola Jr e Hogan (2004), destacam que no atual estágio da modernidade, os hazards tem um nível maior de complexidade, de forma que eles interagem entre si, produzindo os harzards híbridos e quasi-naturais, que são frutos da interação entre os elementos sociais, tecnológicos e naturais. Essa complexidade na análise dos hazards permitiu que outro conceito fosse incorporado a esses estudos, uma vez que ele está relacionado às estruturas socioeconômicas e político-institucionais, que é o da vulnerabilidade.

$\begin{array}{lllll}\text { Caminhos de Geografia } & \text { Uberlândia } & \text { v. 20, n. } 72 & \text { Dez/2019 } & \text { p. 433-453 Página } 435\end{array}$


A vulnerabilidade ao contrário do risco, não possui um consenso entre os cientistas e pesquisadores sobre sua definição exata, uma vez que o termo vulnerabilidade "envolve uma gama de fenômenos de natureza multidimensional e multifacetada, que torna imperativo o diálogo e um olhar mais abrangente diante do tema" (MARANDOLA JR e HOGAN, 2006, p 35). Tem sido utilizada de acordo com Marandola Jr e Hogan (2006, p. 34) como a "idée force" condutora das ações, análises e propostas" por governos mundiais, uma vez que permite a identificação dos riscos e perigos a partir dos aspectos socioespaciais, econômicos e políticos de uma sociedade.

De acordo com Marandola Jr e Hogan (2006), essa convergência teórico-metodológica em torno da vulnerabilidade tem como razão o atual estágio da modernidade, onde alterações geográficas e socialmente estruturais imprimem uma relação mais íntima e complexa entre o risco e a segurança social, que pode ser compreendida a partir da operacionalização do conceito de vulnerabilidade.

Ainda com base em Marandola Jr e Hogan (2006), "a vulnerabilidade sempre será definida a partir de um perigo ou um conjunto deles, em dado contexto geográfico e social", ou seja, a vulnerabilidade pode ser entendida em síntese como "um conjunto de fatores que pode diminuir ou aumentar o(s) risco(s) no qual o ser humano, individualmente ou em grupo, está exposto nas diversas situações da sua vida" (ESTEVES, 2011, p. 69).

Nesse sentido, a vulnerabilidade está ligada a mensuração de quanto um indivíduo, ou grupo, está exposto a um determinado perigo. Sendo assim, diversas metodologias são utilizadas para se quantificar o grau de vulnerabilidade das pessoas ou o grau de exposição de uma determinada área a algum risco. A seguir, encontra-se a metodologia utilizada neste trabalho para definir o grau de vulnerabilidade ambiental da ZPA 9.

\section{APORTE METODOLÓGICO}

Para se definir e identificar uma área como sendo vulnerável do ponto de vista ambiental, é preciso analisar e compreender a dinâmica dos elementos e arranjos naturais que compõem aquele dado espaço, sem claro, isolá-los dos condicionantes sociais, que por sua vez, irão submeter ou não, aquela população a uma situação de risco. Dessa forma, para a identificação da vulnerabilidade ambiental da ZPA 9, a metodologia utilizada foi baseada em Crepani et al. (2001), que se utiliza do conceito da ecodinâmica proposto por Tricart (1977), no qual defende que o relevo é modificado em áreas onde a morfogênese prevalece sobre a pedogênese, ou seja, em áreas que a morfogênese sobressai à pedogênese, mais vulnerável ambientalmente ela estará.

Partindo dessa premissa, Crepani et al. (2001), "propõe valores de vulnerabilidade à perda de solos de acordo com a susceptibilidade que cada elemento possui para o desenvolvimento da morfogênese. Portanto, faz-se necessário apenas consultar as tabelas pré-definidas que foram propostas pelo autor" (MEDEIROS, 2014, p.69).

De acordo com a susceptibilidade de ocorrência dos processos morfodinâmicos são atribuídos valores de vulnerabilidade que variam de 1,0 a 3,0. Nas áreas com valores próximos a 1,0 prevalecem os processos de pedogênese e naquelas cujo valor é mais próximo de 3,0 os processos de morfogênese, denotando mais intensidade e ocorrência de riscos (MEDEIROS, 2014, p.69).

Para esta metodologia é aplicada a análise das unidades de paisagem realizadas a partir dos aspectos físicos da área por meio de mapas temáticos com informações pedológicas, geomorfológicas, geológicas, fitogeográficas e de uso e cobertura do solo, que são sobrepostas a curvas de intensidades pluviométricas. Cada mapa elaborado com os referidos temas citados formam os Planos de Informação (PI) temáticos georreferenciados. Nessa fase são obtidos os PI Geologia, Geomorfologia, Pedologia, Vegetação e Uso do solo. Posteriormente foi realizada a interseção vetorial das unidades territoriais básicas com os polígonos de intervenção antrópica para obtenção do mapa final de vulnerabilidade ambiental.

Com a aplicação da metodologia, atribuiu-se critérios de avaliação das categorias morfodinâmicas, efetuando a classificação de 21 unidades de paisagem na determinação do grau de vulnerabilidade. Esse grau é aplicado a valores na escala de um a três, onde os valores próximos a um correspondem aos processos pedogenéticos. Já no intermediário, até dois, há equilíbrio entre a pedogênese/morfogênese, e às situações de prevalência da morfogênese atribui-se o valor 3, criando os critérios de vulnerabilidade e dividindo-os em classes de análise, tais como: estável, moderamente

$\begin{array}{lllll}\text { Caminhos de Geografia } & \text { Uberlândia } & \text { v. 20, n. } 72 & \text { Dez/2019 } & \text { p. 433-453 Página } 436\end{array}$


Áreas de vulnerabilidade em Natal/RN, Brasil: análise da Zona de Proteção Ambiental 9 (ZPA 9)
Anderson Geová Maia de Brito Lutiane Queiroz de Almeida Marysol Dantas de Medeiros Juliana Felipe Farias

estável, mediamente estável/vulnerável, moderamente vulnerável e vulnerável. Dessa forma dá-se a composição de multicores com base nas três cores aditivas primárias (Azul, Verde e Vermelho) de forma a associar cada classe de vulnerabilidade sempre da mesma cor, obedecendo ao critério de estabilidade, variando entre a composição mais intensa e menos intensa, conforme a tabela 1.

Tabela 1 - Escala de Vulnerabilidade das Unidades Territoriais Básicas.

\begin{tabular}{|c|c|c|c|c|c|c|c|c|}
\hline \multirow{2}{*}{$\begin{array}{c}\begin{array}{c}\text { Unidades } \\
\text { de }\end{array} \\
\text { Paisagem }\end{array}$} & \multicolumn{3}{|c|}{ Média } & $\begin{array}{c}\text { Grau de } \\
\text { Vulnerabilidade }\end{array}$ & \multicolumn{4}{|c|}{ Grau de Saturação } \\
\hline & & & & \multirow{5}{*}{ Vulnerável } & Verm. & Verde & Azul & Cores \\
\hline U1 & & 3,0 & $\triangle$ & & 255 & 0 & 0 & \\
\hline U2 & & 2,9 & & & 255 & 51 & 0 & \\
\hline U3 & & 2,8 & & & 255 & 102 & 0 & \\
\hline U4 & V & 2,7 & & & 255 & 153 & 0 & \\
\hline U5 & $U$ & 2,6 & & \multirow{4}{*}{$\begin{array}{l}\text { Moderadamente } \\
\text { Vulnerável }\end{array}$} & 255 & 204 & 0 & \\
\hline U6 & $\mathrm{L}$ & 2,5 & $E$ & & 255 & 255 & 0 & \\
\hline U7 & $\mathrm{N}$ & 2,4 & $\mathrm{~S}$ & & 204 & 255 & 0 & \\
\hline U8 & $E$ & 2,3 & $\mathrm{~T}$ & & 153 & 255 & 0 & \\
\hline U9 & $\mathrm{R}$ & 2,2 & A & \multirow{5}{*}{$\begin{array}{c}\text { Medianamente } \\
\text { Estável/ Vulnerável }\end{array}$} & 102 & 255 & 0 & \\
\hline U10 & $\mathrm{A}$ & 2,1 & $\mathrm{~B}$ & & 51 & 255 & 0 & \\
\hline U11 & $\mathrm{B}$ & 2,0 & $\mathrm{I}$ & & 0 & 255 & 0 & \\
\hline U12 & 1 & 1,9 & $\mathrm{~L}$ & & 0 & 255 & 51 & \\
\hline U13 & $L$ & 1,8 & I & & 0 & 255 & 102 & \\
\hline U14 & 1 & 1,7 & D & \multirow{4}{*}{$\begin{array}{l}\text { Moderadamente } \\
\text { Estável }\end{array}$} & 0 & 255 & 153 & \\
\hline U15 & D & 1,6 & $\mathrm{~A}$ & & 0 & 255 & 204 & \\
\hline U16 & $\mathrm{A}$ & 1,5 & $\mathrm{D}$ & & 0 & 255 & 255 & \\
\hline U17 & $\mathrm{D}$ & 1,4 & $E$ & & 0 & 204 & 255 & \\
\hline U18 & $E$ & 1,3 & & \multirow{4}{*}{ Estável } & 0 & 153 & 255 & \\
\hline U19 & & 1,2 & & & 0 & 102 & 255 & \\
\hline U20 & 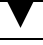 & 1,1 & & & 0 & 51 & 255 & \\
\hline U21 & & 1,0 & & & 0 & 0 & 255 & \\
\hline
\end{tabular}

Fonte: Crepani et al. (2001)

Vale salientar que na metodologia utilizada, adotam-se cinco elementos que são: geologia, geomorfologia, pedologia, vegetação e clima. No caso deste trabalho, consideraram-se apenas quatro variáveis devido ao fator climático não apresentar variações consideráveis. Dessa forma, a cada unidade territorial básica (geologia, geomorfologia, pedologia, vegetação/cobertura e uso do solo), serão atribuídos valores próprios, os quais permitirão através de uma média aritmética, identificar o grau de vulnerabilidade, que se dá a partir da equação seguinte:

$V=G+R+S+V g / U$

4

Onde:

V: vulnerabilidade

G: vulnerabilidade para o tema geologia

R: vulnerabilidade para o tema geomorfologia

S: vulnerabilidade para o tema pedologia

$\mathrm{Vg} / \mathrm{U}$ vulnerabilidade para o tema Vegetação e Uso do Solo 


\title{
O PROCESSO DE INSTITUCIONALIZAÇÃO DAS ZONAS DE PROTEÇÃO AMBIENTAL EM NATAL/RN
}

Questões relativas sobre a preservação ambiental e manutenção das áreas verdes do município, passaram a ser discutidas no primeiro Plano Diretor de Natal (PDN) em 1974 (Lei №2.211 de 10 de julho de 1974), quando em seus Art. $27^{\circ}, 28^{\circ}$ e $29^{\circ}$, são criadas as áreas de preservação permanente, que segundo o Art. $30^{\circ}$, tem por finalidade "resguardar atributos excepcionais da natureza, conciliando a proteção integral da flora e das belezas naturais, com a utilização para objetivos educacionais, recreativos, turísticos e científicos".

Entretanto, cabe salientar, conforme Duarte (2011), que embora constasse no Plano Diretor de Natal de 1974 as áreas de preservação permanente, esse plano não foi efetivamente implementado, "o que fez com que não fossem estabelecidas qualquer fixação de limites, extensão e detalhamento para as áreas integrantes do sistema de setores verdes ali criados". Além disso,

\begin{abstract}
Esse plano foi elaborado sem qualquer participação popular em sua concepção em virtude do contexto político (antidemocrático) no qual se inseria; podendo ser considerado um plano tecnocrático, construído a partir de um ideário racionalista e funcionalista, tendo o desenvolvimento econômico do município como principal preocupação (DUARTE, 2011, p. 52).
\end{abstract}

Em 1984, foi elaborado o segundo Plano Diretor de Natal (Lei № 3.175, de 26 de janeiro de 1984), que instituiu a Área de Preservação Permanente (APP), áreas que em seu Art. $9^{\circ}$, foram definidas como tais, "por suas características físicas, ecológicas, culturais, históricas ou paisagísticas exijam cuidados de manutenção ou restauração de seu estado, a fim de proteger, preservar ou recuperar o meio ambiente e os patrimônios naturais e culturais do município".

De acordo com o PDN/84 em seus Art. $11^{\circ}, 192^{\circ}$ e $193^{\circ}$, as APPs englobariam praças, bosques, rios, lagos e lagoas, e coberturas vegetais, que segundo Duarte (2011) visavam "proteger sítios de beleza e valor paisagístico, natural, científico ou histórico". Este plano deu uma atenção maior a questão ambiental e demonstrou real preocupação com o quadro físico e natural de Natal.

Entretanto vale destacar que naquela época (década de 1990), segundo Bentes Sobrinha (1993, p. 15), a questão ambiental era tratada de forma restrita, "sem que fossem considerados esses elementos como parte de um território que apresenta conflitos", o que causou preocupação entre os diversos agentes que atuam na sua produção.

As atuais ZPAs do município de Natal/RN tiveram origem em 1994 a partir da elaboração do Plano Diretor deste mesmo ano (Lei complementar $n^{\circ} 2.211$, de 5 de agosto de 1994). Seguindo os princípios da Constituição Federal de 1988, este Plano Diretor estabeleceu o zoneamento de Natal através de características históricas, sociais, paisagísticas e ambientais como orientação para o uso e ocupação do solo, estabelecendo a:I - Zona de Adensamento Básico; II - Zona Adensável; e III - Zona de Proteção Ambiental.

O PDN/1994 define a ZPA como a área em que "as características do meio físico, restringem o uso e ocupação do solo urbano, visando à proteção, manutenção e recuperação dos aspectos paisagísticos, históricos, arqueológicos e científicos". E "para efeito dos critérios de sua utilização", de acordo as formas de aproveitamento paisagístico, uso e ocupação do solo e preservação ambiental, a ZPA foi subdividida no Art. $21^{\circ}$ do PDN/1994 em: I - Subzona de Preservação e II - Subzona de Conservação.

Após treze anos, o PDN/94 foi revisado, sendo atualmente a Lei Complementar no 082, de 21 de junho de 2007, mantendo os princípios do PDN/1994 e os Zoneamentos nele previstos, definindo as ZPAs em seu Art. $17^{\circ}$ como áreas em que "as características do meio físico restringem o uso e ocupação, visando a proteção, manutenção e recuperação dos aspectos ambientais, ecológicos, paisagísticos, históricos, arqueológicos, turísticos, culturais, arquitetônicos e científicos".

E com base nos planos anteriores, o PDN/2007 a partir de técnicas de geoprocessamento mais sofisticadas, descreve e institui 10 ZPA, algumas até aquele ano regulamentadas, tal qual como consta em seu Art. $18^{\circ}$ e pode ser observado na figura 2.

$\begin{array}{llllll}\text { Caminhos de Geografia } & \text { Uberlândia } & \text { v. 20, n. } 72 & \text { Dez/2019 } & \text { p. 433-453 Página } 438\end{array}$


Figura 2 - Carta-imagem das Zonas de Proteção Ambiental em Natal/RN.

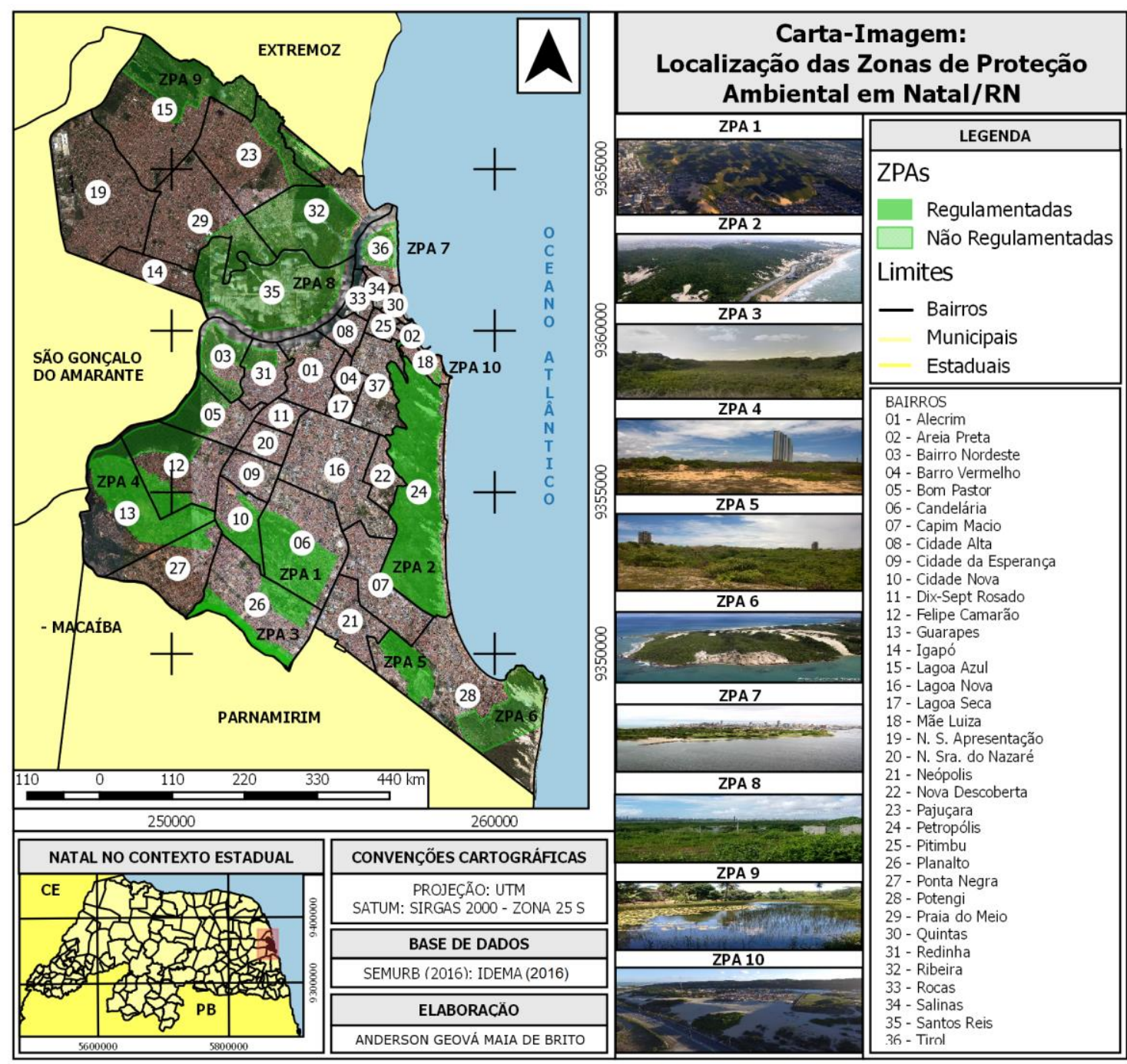

Fonte: elaboração dos autores.

Como pode ser observado no mapa da figura 2, as ZPAs ocupam áreas extensas do município de Natal, $51,21 \mathrm{Km}^{2}$ mais precisamente, o que representa $30 \%$ área total do município. Segundo Azevedo (2010), as ZPAs por terem a dimensão espacial que tem, acabam funcionando como verdadeiros amenizadores climáticos e purificadores de ar da cidade, além de servirem de refúgio a flora e fauna, como também são responsáveis pela recarga hídrica dos rios, lagoas e lençóis freáticos, pela redução dos processos erosivos e pela manutenção da beleza paisagística e visual da cidade.

E por ocuparem uma área tão extensa, as ZPAs tornam-se vulneráveis a pressão imobiliária, o que em muitas vezes, acaba por produzir conflitos judiciais e socioespaciais, principalmente no bairro de Ponta Negra, onde está localizada a ZPA 6 (Morro do Careca). Dessa forma, conforme destaca Duarte (2011, p. 347), estes importantes espaços ambientais na cidade de Natal/RN, "deixam de servir como instrumento de concretização/efetivação do direito fundamental ao meio ambiente, considerando o objetivo da sustentabilidade (social e econômica)" para atender os interesses do Capital.

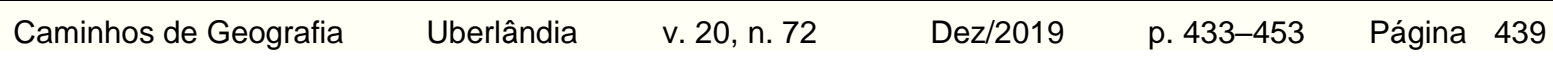


Áreas de vulnerabilidade em Natal/RN, Brasil: análise da Zona de Proteção Ambiental 9 (ZPA 9)
Anderson Geová Maia de Brito Lutiane Queiroz de Almeida Marysol Dantas de Medeiros Juliana Felipe Farias

\section{PLANO DE INFORMAÇÃO (P.I) DE GEOLOGIA}

A área de estudo é formada por conglomerados argilito-arenosos e principalmente por sedimentos inconsolidados que são transportados pela ação da gravidade, constituídos por depósitos de areia, cascalho e argila, que estão altamente vulneráveis as ações intempéricas. Dentre as formações geológicas, há a Formação/Grupo Barreiras que é um conglomerado argilito-arenoso presente em toda a costa oriental, os Depósitos de mangues que se encontram na planície Flúvio-marinha do rio Potengi, sendo constituídos litologicamente por turfa, lama, areia e argila, e os Depósitos Eólicos Litorâneos, que se subdividem em depósitos de Paleodunas que são vegetetados e em depósitos eólicos, que estão sob a ação constante do vento, são litologicamente constituídos apenas depósitos de areias e silte, que por sinal são materiais bastante friáveis, conforme pode ser observado na tabela 2.

Tabela 2 - Tabela síntese Grau do PI de Geologia da ZPA 9.

\begin{tabular}{l|l|c}
\hline \multicolumn{1}{c|}{ ROCHAS } & \multicolumn{1}{c}{ FORMAÇÃO GEOLÓGICA } & VULNERABILIDADE \\
\hline $\begin{array}{l}\text { Conglomerado: argilito - } \\
\text { arenosoarenito - conglomerático. }\end{array}$ & Formação Barreiras & $\mathbf{2 , 5}$ \\
\hline $\begin{array}{l}\text { Sedimentos Inconsolidados: } \\
\text { areia, argila e cascalho. }\end{array}$ & $\begin{array}{l}\text { Depósitos Eólicos Litorâneos de } \\
\text { Paleodunas }\end{array}$ & $\mathbf{3 , 0}$ \\
\hline $\begin{array}{l}\text { Sedimentos Inconsolidados: } \\
\text { areia }\end{array}$ & $\begin{array}{l}\text { Depósitos Eólicos Litorâneos de } \\
\text { Praia e Duna }\end{array}$ & 3,0 \\
\hline $\begin{array}{l}\text { Sedimento sInconsolidados: } \\
\text { turfa, lama argila e areia. }\end{array}$ & Depósitos de Mangues & 3,0 \\
\hline
\end{tabular}

Fonte: elaboração dos autores a partir de Crepani et al (2001).

Desta forma para elaborar o mapa do PI de Geologia e o de vulnerabilidade geológica da área estudada, foram utilizados as informações e os dados de mapas digitais do Serviço Geológico Brasileiro (CPRM) na escala de 1:100.000, que posteriormente foram processadas pelo programa Quantum GIS 2.14 - Essen, produzindo os mapas das figuras 3 e 4.

Figura 3 - Mapa Geológico da ZPA 9.

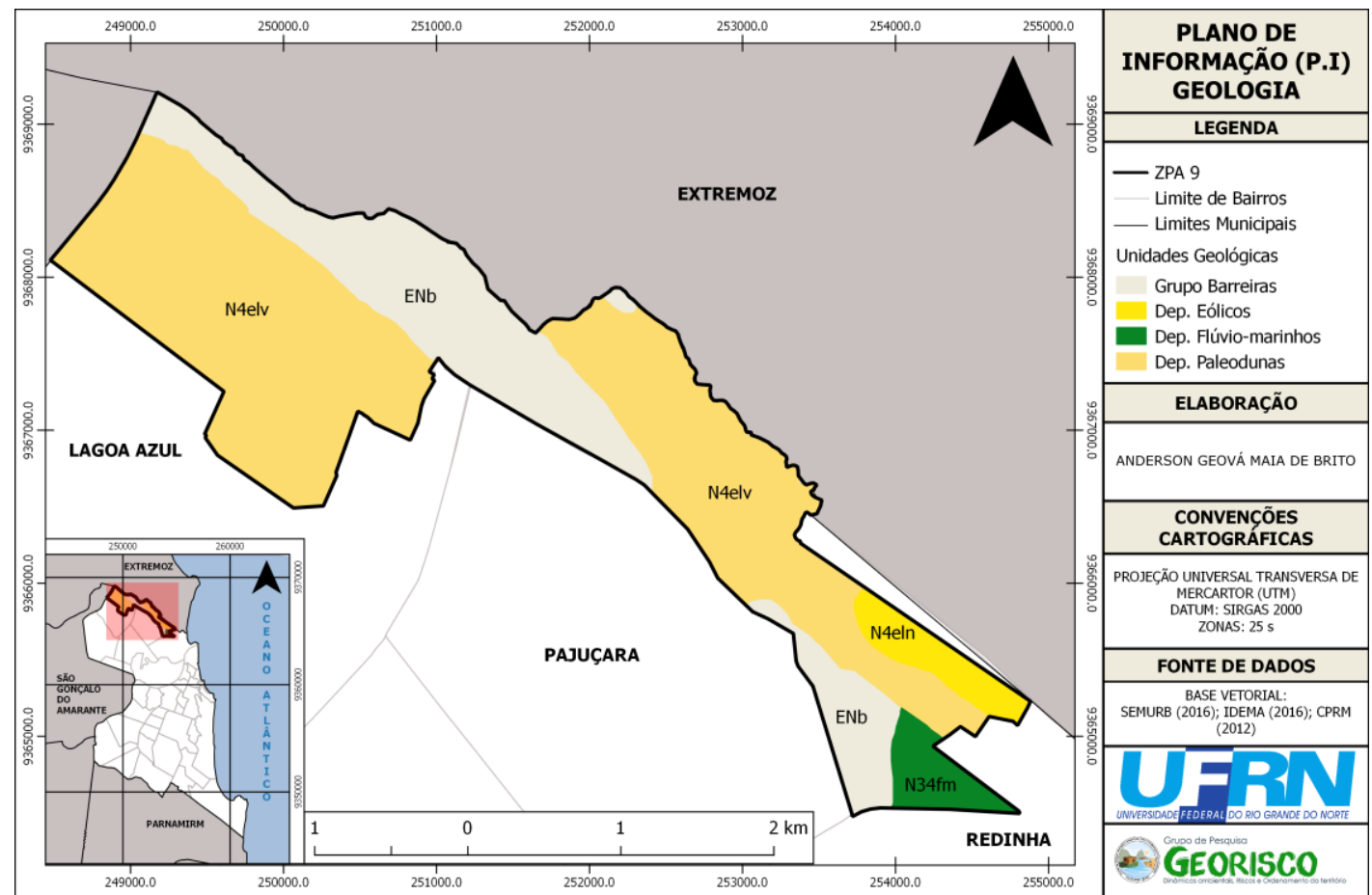

Fonte: elaboração dos Autores.

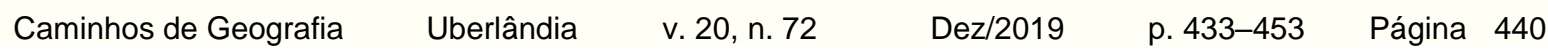


Figura 4 - Mapa de Vulnerabilidade da ZPA 9.

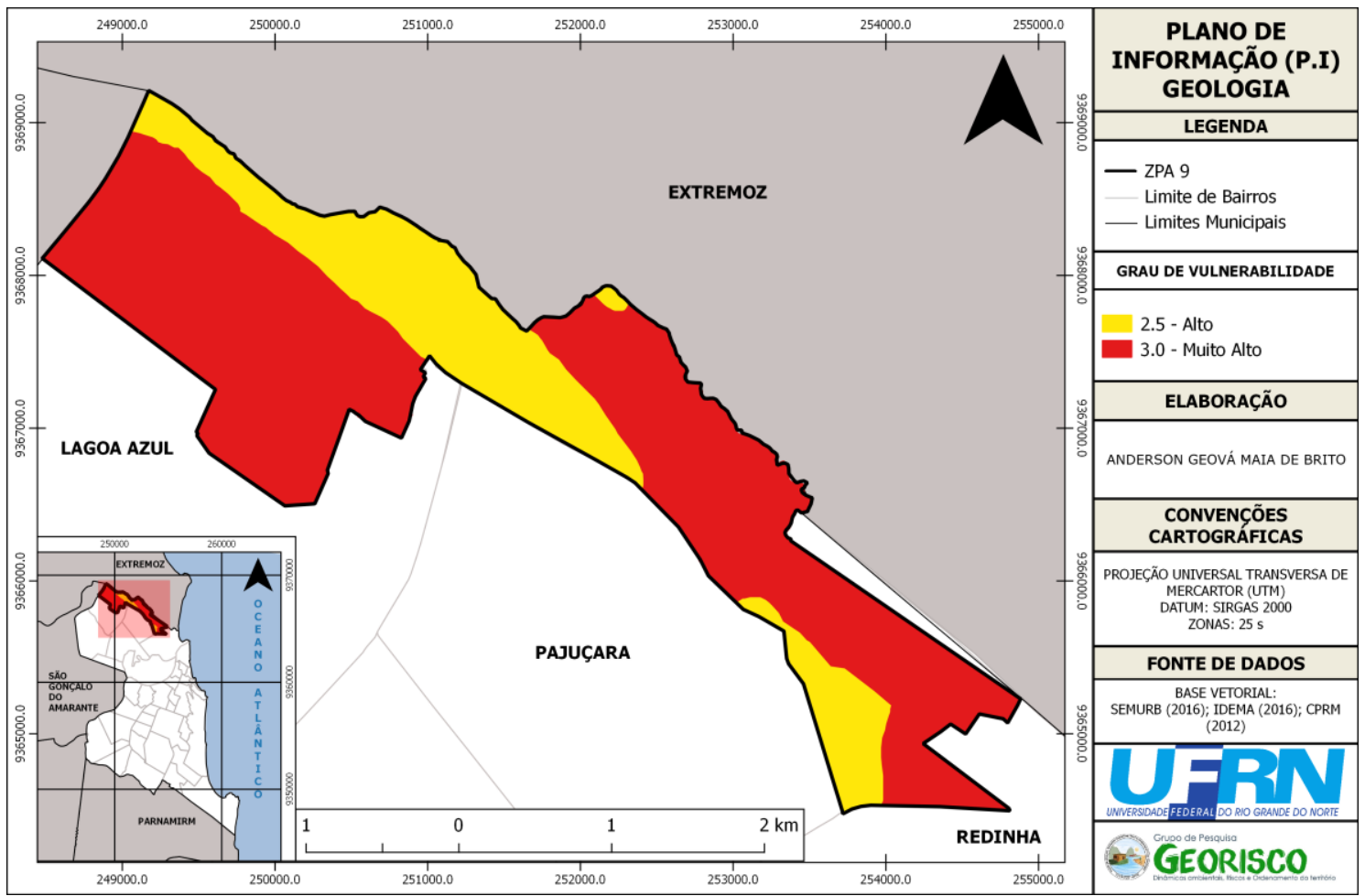

Fonte: elaboração dos Autores.

\section{PLANO DE INFORMAÇÃO (P.I) DE PEDOLOGIA}

A metodologia da pesquisa parte do princípio que solos mais maduros são mais estáveis devido a sua porosidade e profundidade e solos menos maduros são mais instáveis pela facilidade de intemperização. Dessa forma, o valor atribuído as unidades de solo consideradas estáveis na escala de vulnerabilidade é 1,0 , sendo estes na área de estudo representados pela classe dos Latossolos, que são solos bem desenvolvidos, com grande profundidade e com ausência parcial ou total de materiais intemperizáveis. No valor 2 estão os solos da classe dos Podzólicos, que são solos de pouca profundidade, menos estáveis e mais intemperizáveis. Os solos que possui o valor três na escala de vulnerabilidade são jovens, pouco desenvolvidos, alguns desnudos e com forte ação intempérica conforme pode ser consultado na tabela 3, elaborada a partir de Crepani et at., (2001) com base nos dados da Empresa Brasileira de Pesquisa Agropecuária (EMPRAPA) do ano de 2006.

Tabela 3 - Tabela síntese do PI de Pedologia da ZPA 9.

\begin{tabular}{c|l|c}
\hline SOLOS & \multicolumn{1}{|c|}{ CARACTERÍSTICAS PRINCIPAIS } & VULNERABILIDADE \\
\hline $\begin{array}{c}\text { Latossolos Amarelos } \\
\text { (LA) }\end{array}$ & $\begin{array}{l}\text { Maduros, profundos, lixiviados, porosos } \\
\text { e permeáveis. }\end{array}$ & 1,0 \\
\hline $\begin{array}{c}\text { Neossolos Quartzarênicos } \\
\text { (RQ) }\end{array}$ & $\begin{array}{l}\text { Jovens, ausência de matéria orgânica e } \\
\text { argila, excessivamente porosos e } \\
\text { facilmente erodidos. }\end{array}$ & 3,0 \\
\hline
\end{tabular}

Fonte: elaboração dos autores.

Como pode ser observado na tabela acima, a ZPA 9 apresenta dois extremos no que se refere a vulnerabilidade do solo, se dividindo nesse caso em Latossolo Amarelo de baixa vulnerabilidade e Neossolo Quartzarênico com uma vulnerabilidade altamente elevada. Com base nisso e nos dados vetoriais da CPRM da carta Natal, o PI Pedologia e de vulnerabilidade pedológica pode ser representado cartograficamente como nas figuras 5 e 6 .

$\begin{array}{lllll}\text { Caminhos de Geografia } & \text { Uberlândia } & \text { v. 20, n. } 72 & \text { Dez/2019 } & \text { p. 433-453 Página } 441\end{array}$


Figura 5 - Mapa de Pedologia da ZPA 9.

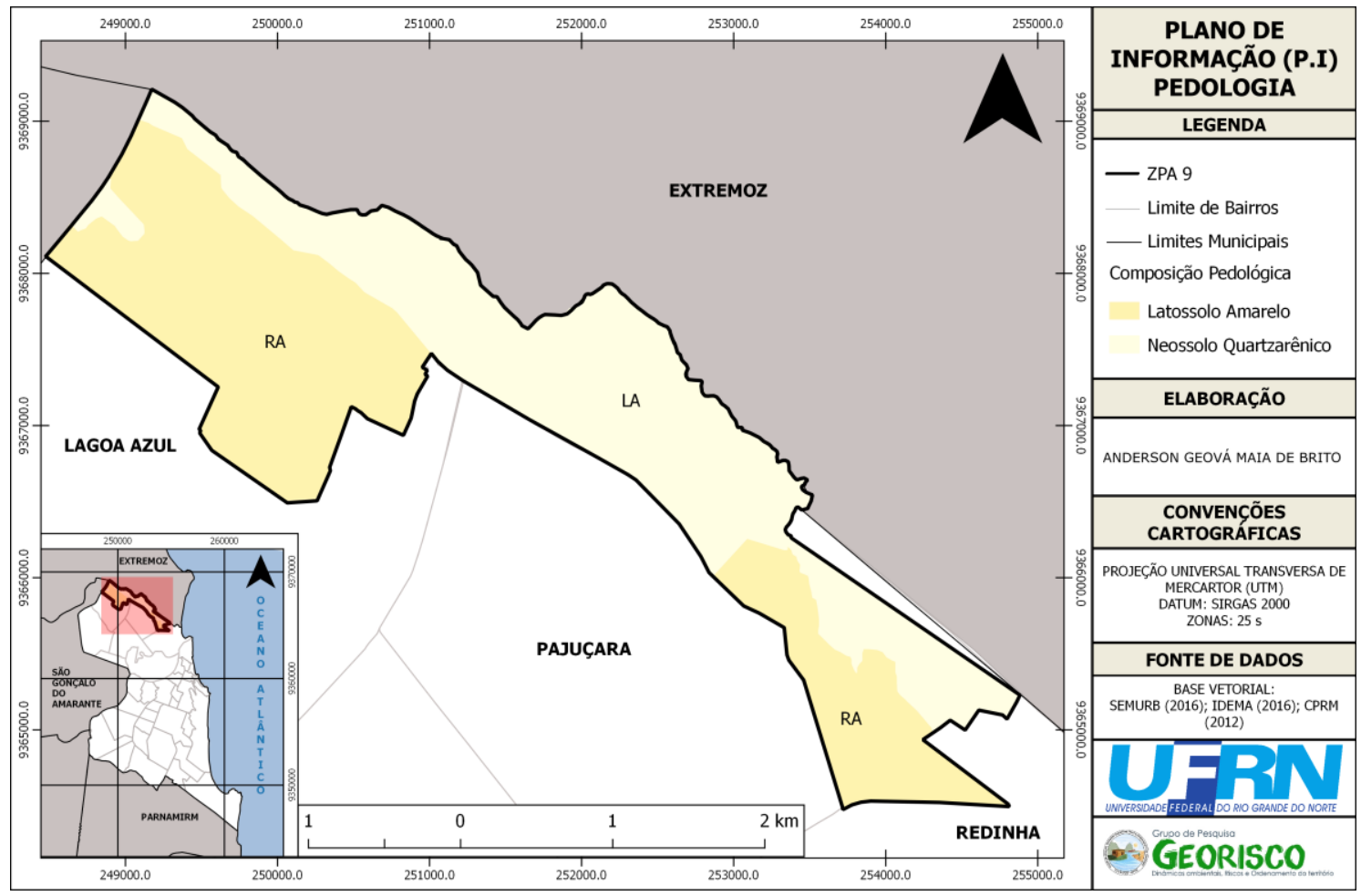

Fonte: elaboração dos Autores.

Figura 6 - Mapa de Vulnerabilidade da Pedologia da ZPA 9.

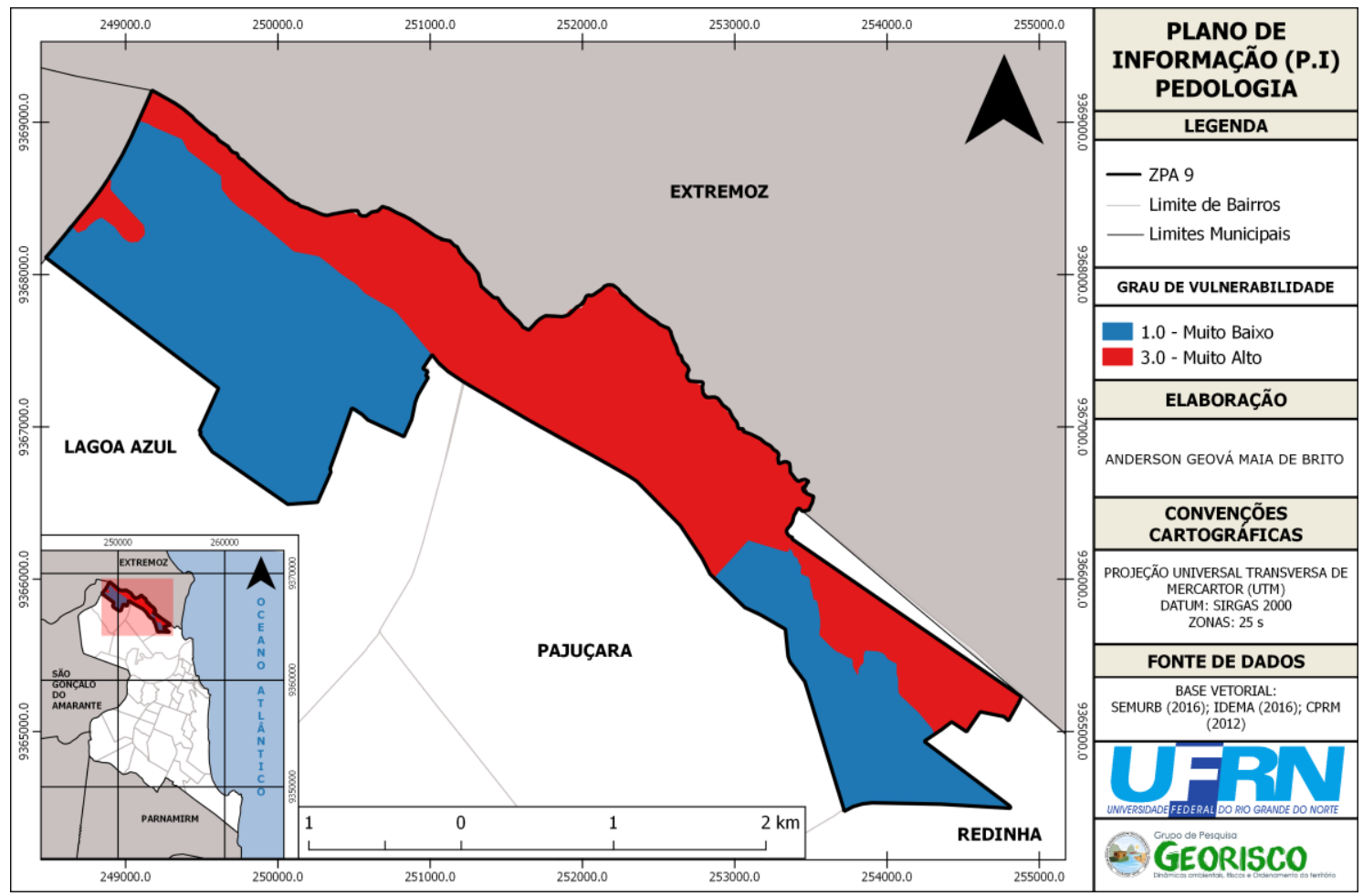

Fonte: elaboração dos Autores. 
Áreas de vulnerabilidade em Natal/RN, Brasil: análise da Zona de Proteção Ambiental 9 (ZPA 9)
Anderson Geová Maia de Brito Lutiane Queiroz de Almeida Marysol Dantas de Medeiros Juliana Felipe Farias

\section{PLANO DE INFORMAÇÃO (P.I) DE GEOMORFOLOGIA}

Para a identificação do grau de vulnerabilidade da geomorfologia, a metodologia utilizada baseia-se na morfometria do relevo (tabelas 4 e 5), que considera a capacidade do relevo de transformar a energia cinética em energia potencial gravitacional, ou seja, quanto mais íngreme o terreno for, mais facilidade os materiais dessa encosta terão de deslizar.

A partir da média aritmética entre os Pls de Altimetria e Declividade foi possível obter o PI final de vulnerabilidade Geomorfológica, e como pode ser observado, a maior parte da ZPA 9 se enquadra em médias que variam entre 1,5 (moderamente estável) e 2,2 (medianamente estável), áreas em progressão amarela que correspondem a cordões e colinas dunares, com exceção da pequena faixa azul de média entre 1,0 e 1,2 (estável).

Tabela 4. Escala de Vulnerabilidade/Estabilidade para amplitude altimétrica.

\begin{tabular}{c|c|c|c|c|c}
\hline $\begin{array}{c}\text { AMPLITUDE } \\
\text { ALTIMÉTRICA }(\mathbf{m})\end{array}$ & $\begin{array}{c}\text { VULN./ } \\
\text { ESTAB. }\end{array}$ & $\begin{array}{c}\text { AMPLITUDE } \\
\text { ALTIMÉTRICA }(\mathbf{m})\end{array}$ & $\begin{array}{c}\text { VULN./ } \\
\text { ESTAB. }\end{array}$ & $\begin{array}{c}\text { AMPLITUDE } \\
\text { ALTIMÉTRICA }(\mathbf{m})\end{array}$ & $\begin{array}{c}\text { VULN./ } \\
\text { ESTAB. }\end{array}$ \\
\hline$<20$ & 1,0 & $77-84,5$ & 1,7 & $141,5-151$ & 2,4 \\
\hline $20-29,5$ & 1,1 & $84,5-94$ & 1,8 & $151-160,5$ & 2,5 \\
\hline $29,5-39$ & 1,2 & $94-103,5$ & 1,9 & $160,5-170$ & 2,6 \\
\hline $39-48,5$ & 1,3 & $103,5-113$ & 2,0 & $170-179,5$ & 2,7 \\
\hline $48,5-58$ & 1,4 & $113-122,5$ & 2,1 & $179,5-189$ & 2,8 \\
\hline $58-67,5$ & 1,5 & $122,5-132$ & 2,2 & $189-200$ & 2,9 \\
\hline $67,5-77$ & 1,6 & $132-141,5$ & 2,3 & $>200$ & 3,0 \\
\hline
\end{tabular}

Fonte: adaptado pelos autores a partir de Crepani et al. (2001).

Tabela 5 - Escala de Vulnerabilidade/Estabilidade Vulnerabilidade para Declividade.

\begin{tabular}{c|c|c|c|c|c}
\hline DECLIVIDADE (\%) & $\begin{array}{c}\text { VULN./ } \\
\text { ESTAB. }\end{array}$ & DECLIVIDADE (\%) & $\begin{array}{c}\text { VULN./ } \\
\text { ESTAB. }\end{array}$ & DECLIVIDADE (\%) & $\begin{array}{c}\text { VULN./ } \\
\text { ESTAB. }\end{array}$ \\
\hline$<3,5$ & 1,0 & $17,4-19,8$ & 1,7 & $34,6-37,2$ & 2,4 \\
\hline $3,5-5,8$ & 1,1 & $19,8-22,2$ & 1,8 & $37,2-39,8$ & 2,5 \\
\hline $5,8-8,2$ & 1,2 & $22,2-24,5$ & 1,9 & $39,8-42,4$ & 2,6 \\
\hline $8,2-10,3$ & 1,3 & $24,5-27,2$ & 2,0 & $42,4-45,3$ & 2,7 \\
\hline $10,3-12,9$ & 1,4 & $27,2-29,6$ & 2,1 & $45,3-48,1$ & 2,8 \\
\hline $12,9-15,1$ & 1,5 & $29,6-32,1$ & 2,2 & $48,1-50$ & 2,9 \\
\hline $15,1-17,4$ & 1,6 & $32,1-34,6$ & 2,3 & $>50$ & 3,0 \\
\hline
\end{tabular}

Fonte: adaptado pelos autores a partir de Crepani et al. (2001).

Assim, na elaboração do PI geomorfologia, foi utilizado o mapa topográfico do Programa Regional de Desenvolvimento do Turismo (PRODETUR) com curvas de nível de um em um metros, a partir do qual se elaborou os mapas de declividade e altimetria no programa Quantum GIS 2.14 - Essen, que sobrepostos, forneceram o mapa de vulnerabilidade geomorfológica da ZPA 9, conforme observa-se nas figuras 7, 8 e 9 .

Figura 7 - Mapa de Altimetria (A) e vulnerabilidade da altimetria (B).

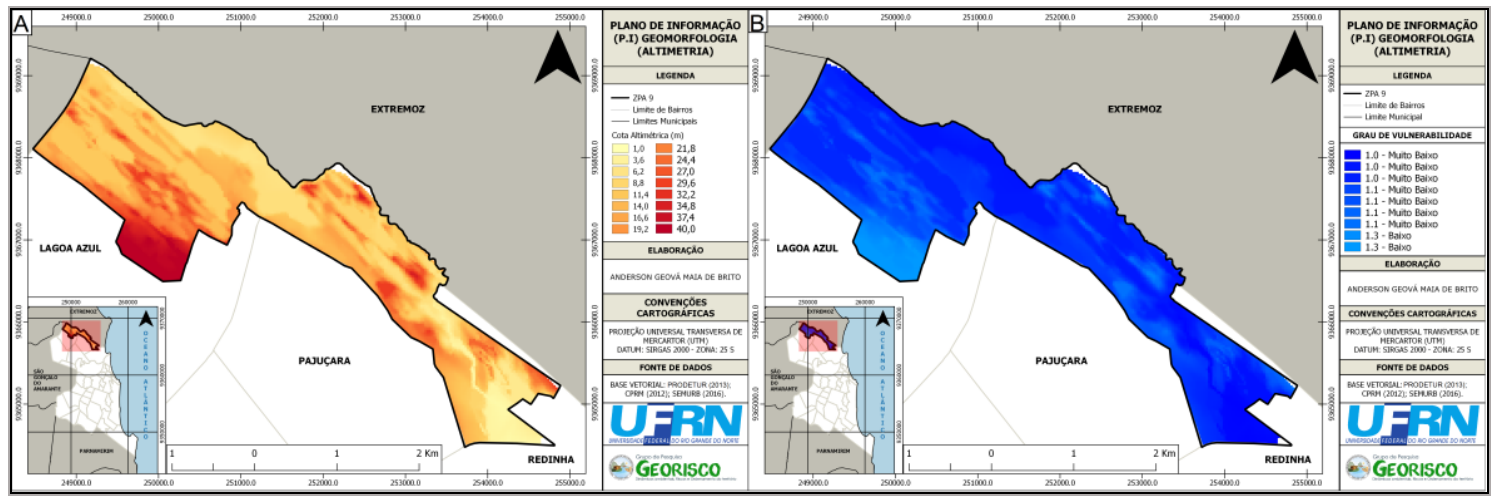

Fonte: elaboração dos autores.

$\begin{array}{llllll}\text { Caminhos de Geografia } & \text { Uberlândia } & \text { v. 20, n. } 72 & \text { Dez/2019 } & \text { p. 433-453 } & \text { Página } 443\end{array}$


Figura 8 - Mapa de Declividade (A) e vulnerabilidade de declividade (B) da ZPA 9.

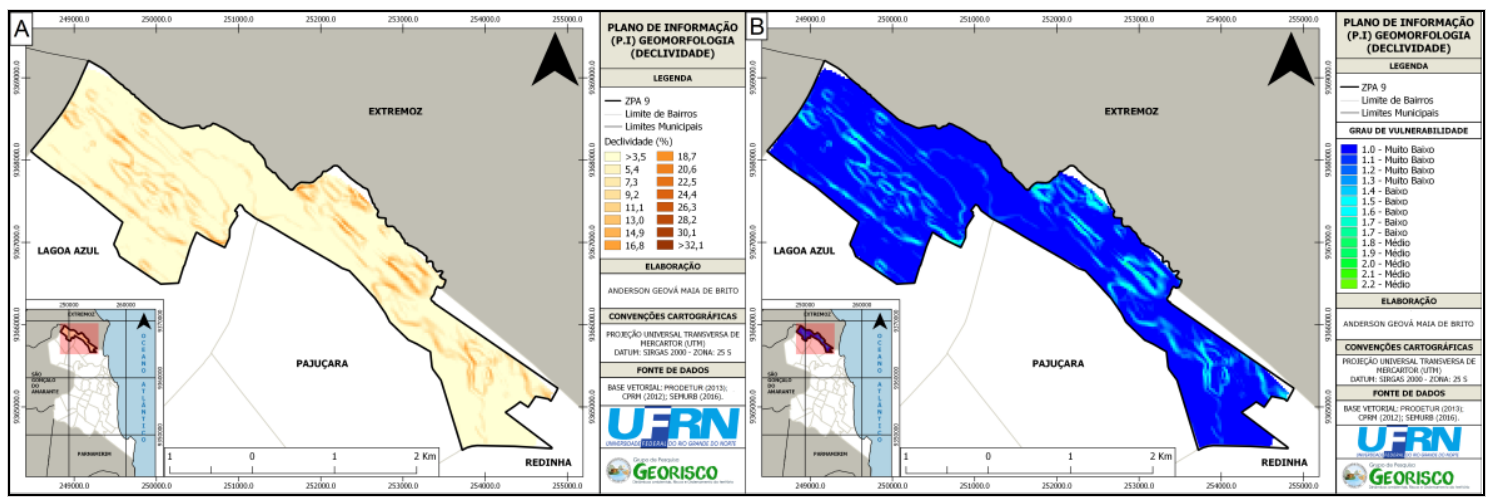

Fonte: elaboração dos autores.

Figura 9 - Mapa de Vulnerabilidade da Geomorfologia da ZPA 9.

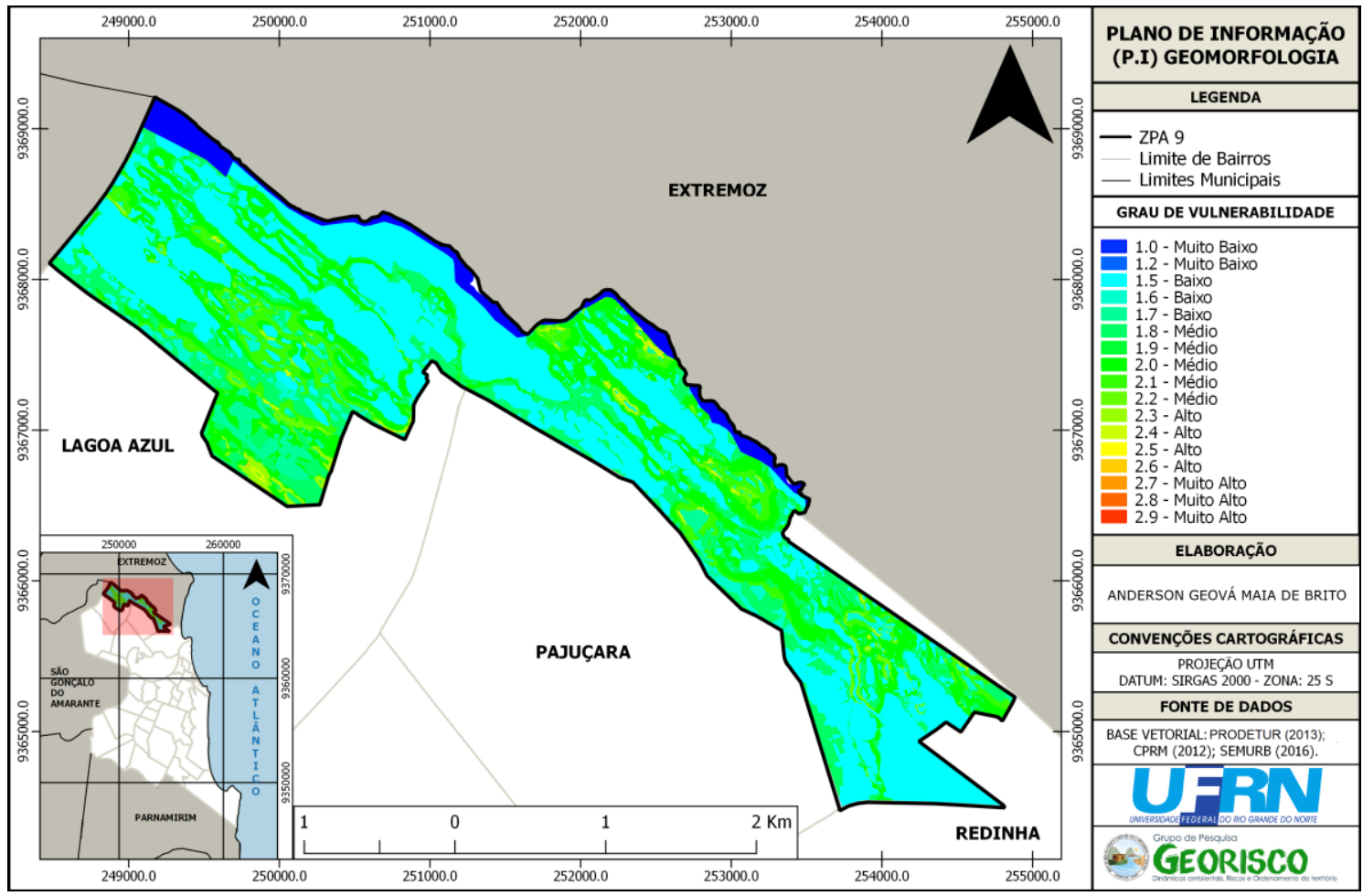

Fonte: elaboração dos autores.

\section{PLANO DE INFORMAÇÃO (P.I) DE USO E COBERTURA DO SOLO}

A densidade da cobertura vegetal de uma unidade de paisagem natural (cobertura do terreno) é um fator de proteção contra os processos intempéricos e morfogenéticos que se caracterizam por erosão, a metodologia desta pesquisa atribui o valor 1,0 na escala de vulnerabilidade aos conjuntos vegetais mais densos, e valores de 2,0 a densidades intermediárias e três para coberturas vegetais com baixas densidades.

Além da cobertura vegetação, foram confeccionados para este PI outras unidades ambientais, como o rio Doce, as lagoas interdunares e fluviais e as dunas não vegetadas, e também as áreas antropizadas na ZPA 9, onde se destacam os campos agrícolas, as áreas já urbanizadas ou em processo de urbanização. Embora a metodologia utilizada por Crepani et al. (2001) não traga os valores e médias de vulnerabilidade para estas áreas, os valores a elas atribuídos partiram da

\begin{tabular}{llllll}
\hline Caminhos de Geografia & Uberlândia & v. 20, n. 72 & Dez/2019 & p. 433-453 Página 444
\end{tabular}


Áreas de vulnerabilidade em Natal/RN, Brasil: análise da Zona de Proteção Ambiental 9 (ZPA 9)
Anderson Geová Maia de Brito Lutiane Queiroz de Almeida Marysol Dantas de Medeiros Juliana Felipe Farias

vulnerabilidade das unidades de paisagem natural e dos polígonos de intervenção antrópica, conforme pode ser observado na tabela 6 .

Tabela 6 - Tabela síntese do PI Uso e Cobertura do Solo da ZPA 9.

\begin{tabular}{c|l|c}
\hline COBERTURA/USO & \multicolumn{1}{|c}{ CARACTERÍSTICAS PRINCIPAIS } & VULNERABILIDADE \\
\hline Restinga Arbórea & $\begin{array}{l}\text { É facilmente encontrada fixando as Paleodunas que } \\
\text { formam os cordões interdunares da cidade. }\end{array}$ & $\mathbf{1 , 4}$ \\
\hline Restinga Arbustiva & $\begin{array}{l}\text { É facilmente encontrada fixando as Paleodunas que } \\
\text { formam os cordões interdunares. }\end{array}$ & $\mathbf{2 , 3}$ \\
\hline Restinga Herbácea & $\begin{array}{l}\text { Ocorrem nas faixas de dunas ou ante-dunas, em } \\
\text { locais que eventualmente podem ser alagáveis. }\end{array}$ & $\mathbf{2 , 7}$ \\
\hline $\begin{array}{c}\text { Vegetação de } \\
\text { Influência Fluvial }\end{array}$ & $\begin{array}{l}\text { Se localiza nos ambientes das várzeas úmidas e } \\
\text { alagadas e em periferias de cursos d'água. }\end{array}$ & $\mathbf{2 , 7}$ \\
\hline $\begin{array}{c}\text { Área Fracamente } \\
\text { Urbanizada }\end{array}$ & $\begin{array}{l}\text { Áreas de baixa ocupação residencial e } \\
\text { impermeabilização do solo. }\end{array}$ & $\mathbf{2 , 7}$ \\
\hline $\begin{array}{c}\text { Área Densamente } \\
\text { Urbanizada }\end{array}$ & $\begin{array}{l}\text { Áreas de forte pressão urbana, com alguns locais } \\
\text { sem planejamento. }\end{array}$ & $\mathbf{2 , 8}$ \\
\hline Campos Agrícolas & Áreas destinadas ao plantio ou criação de animais. & $\mathbf{2 , 8}$ \\
\hline Duna Desnuda & $\begin{array}{l}\text { Apresenta solo completamente exposto e } \\
\text { vulnerável as ações intempéricas. }\end{array}$ & 3,0 \\
\hline Lagoas & $\begin{array}{l}\text { Afloram a partir da ressurgência do lençol freático ou } \\
\text { são de origem artificial. }\end{array}$ & 3,0 \\
\hline Rio & Curso de água natural passível de assoreamento. & 3,0 \\
\hline
\end{tabular}

Fonte: elaboração dos autores.

Desta forma, para a confecção do mapa do $\mathrm{PI}$, foi necessária a utilização de fotos aéreas do PRODETUR, onde as áreas checadas em campo foram vetorizadas através do programa Quantum GIS 2.14 - Essen, sendo assim delimitadas as principais ocorrências de vegetação encontradas na área de estudo, bem como os corpos hídricos e as principais formas de uso e ocupação do solo, como podem ser observadas nas figuras 10 e 11.

Figura 10 - Mapa de Uso e Cobertura do Solo da ZPA 9.

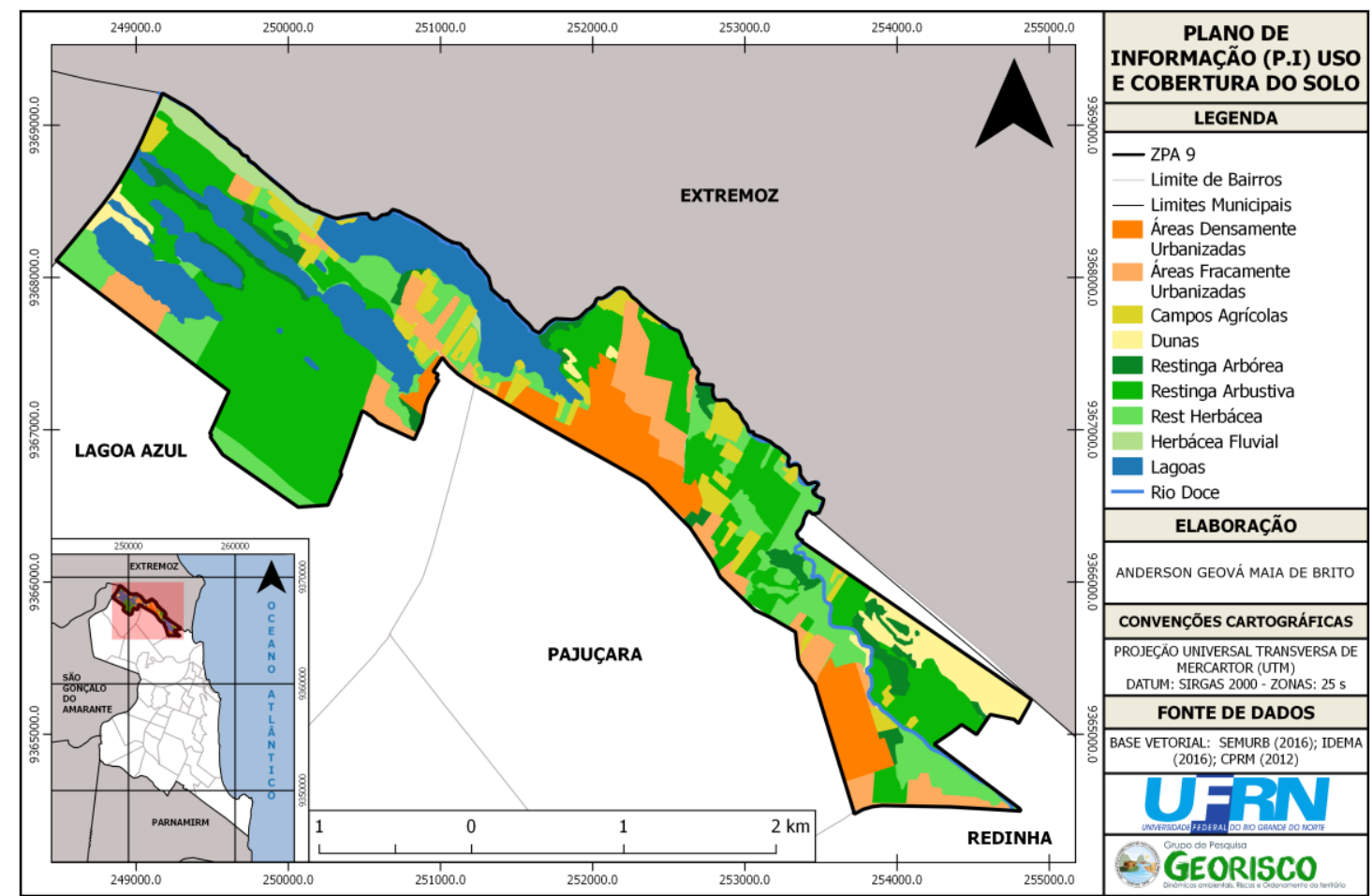

Fonte: elaboração dos autores.

$\begin{array}{lllll}\text { Caminhos de Geografia } & \text { Uberlândia } & \text { v. 20, n. } 72 & \text { Dez/2019 } & \text { p. 433-453 Página } 445\end{array}$


Figura 11 - Mapa de Vulnerabilidade do Uso e Ocupação do Solo da ZPA 9.

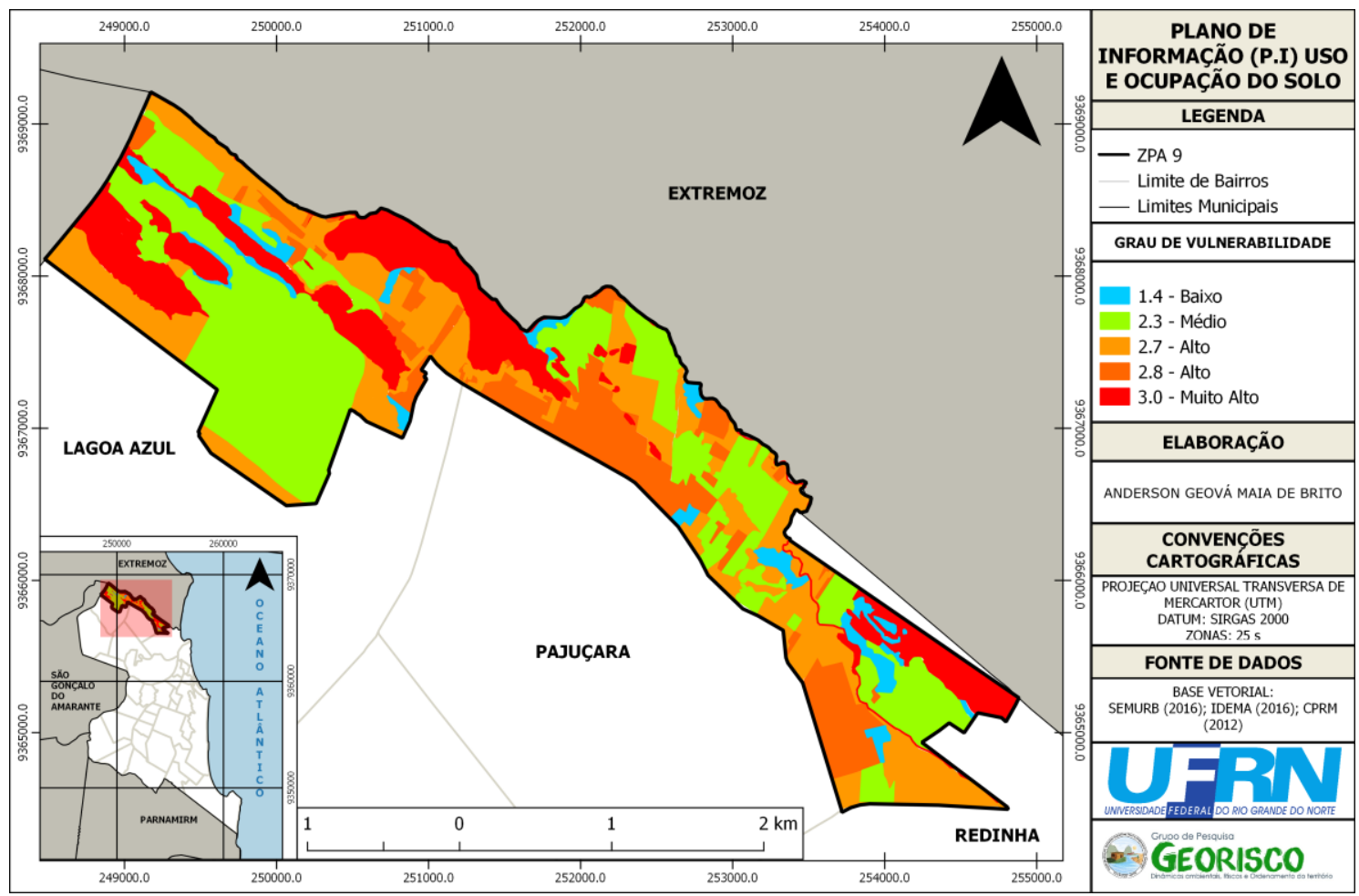

Fonte: elaboração dos autores.

\section{VULNERABILIDADE AMBIENTAL DA ZONA DE PROTEÇÃO AMBIENTAL (ZPA) 9}

Como produto final do trabalho, foi elaborado o mapa de vulnerabilidade ambiental, constituído a partir da sobreposição e intersecção dos mapas temáticos confeccionados com as informações de todos os PI da área. A sobreposição foi realizada através das ferramentas de geoprocessamento disponibilizadas pelo programa Quantum GIS 2.14 - Essen, o que nos permitiu identificar as áreas com menor, médio e maior grau de vulnerabilidade levando em consideração a média aritmética obtida através da aplicação da equação da metodologia, como pode ser constatado na tabela 7 e na figura 12.

Tabela 7 - Escala de vulnerabilidade (RGB) da ZPA 9.

\begin{tabular}{c|c|c}
\hline MÉDIA & GRAU DE VULNERABILIDADE & COR RESPECTIVA \\
\hline 1,6 & Moderamente Estável & \\
\hline 1,7 & Moderamente Estável & \\
\hline 1,8 & Medianamente Estável/Vulnerável & \\
\hline 1,9 & Medianamente Estável/Vulnerável & \\
\hline 2,0 & Medianamente Estável/Vulnerável & \\
\hline 2,1 & Medianamente Estável/Vulnerável Estável/Vulnerável & \\
\hline 2,2 & Moderamente Vulnerável & \\
\hline 2,3 & ModeramenteVulnerável & \\
\hline 2,4 & Moderamente Vulnerável & \\
\hline 2,5 & Moderamente Vulnerável & \\
\hline 2,6 & Vulnerável & \\
\hline 2,7 & Vulnerável & \\
\hline 2,8 & Vulnerável & \\
\hline 2,9 & Vulnerável & \\
\hline 3,0 & &
\end{tabular}

Fonte: elaborado pelos autores a partir de Crepani et al. (2001).

$\begin{array}{lllll}\text { Caminhos de Geografia } & \text { Uberlândia } & \text { v. 20, n. } 72 & \text { Dez/2019 } & \text { p. 433-453 Página } 446\end{array}$


Figura 12 - Vulnerabilidade Ambiental da ZPA 9.

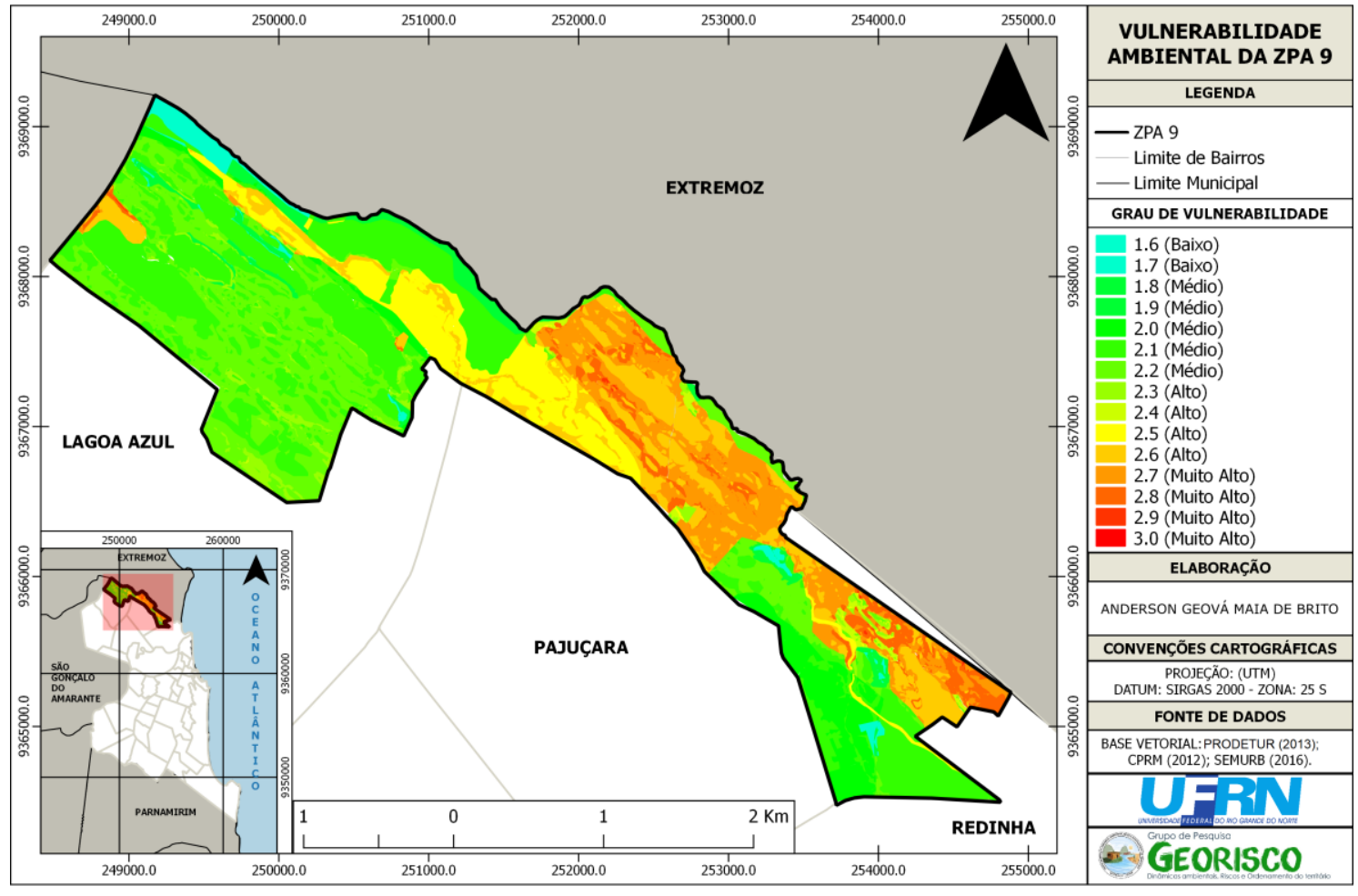

Fonte: elaboração dos autores.

Com base no mapa da figura 11, e na metodologia de Crepani et al (2001), pode-se constatar que nenhuma área da ZPA 9 possui estabilidade, uma vez que para isso ocorrer algumas médias devem estar entre 1,0 e 2,0, o que a situa em um quadro de vulnerabilidade entre moderamente estável e vulnerável, que na representação pela classificação RGB de cores utilizada, a progressão do azul ao vermelho significa aumento no grau de vulnerabilidade e o verde corresponde a uma estabilidade maior.

As áreas na escala de amarelo a vermelho no mapa, ou seja, aquelas que estão no centro da ZPA, são as de maior vulnerabilidade, e correspondem as áreas urbanas, as encostas do vale do Rio Doce e as dunas com vegetação herbácea ou sem vegetação. As áreas urbanas possuem um grau de vulnerabilidade alto uma vez que as infraestruturas e equipamentos urbanos nestas localidades são ínfimos, não só resultado do acelerado processo de expansão urbana irregular como por estarem situadas ao longo do vale do Rio Doce e nas dunas adjacentes a ele, que possuem o mais alto grau de vulnerabilidade, com médias de 2,7 a 3, uma vez que também o solo desta área da ZPA 9 é do tipo Nessolo Quartazrênico, como pode ser consultado nas figuras 13 e 14:

Figura 13 - Ocupação por residências no topo (interflúvio) da encosta do Rio Doce (A); Canaletas de vazão em rodovia sob Rio Doce (B); Desnudação de encosta e assoreamento do Rio Doce (C).

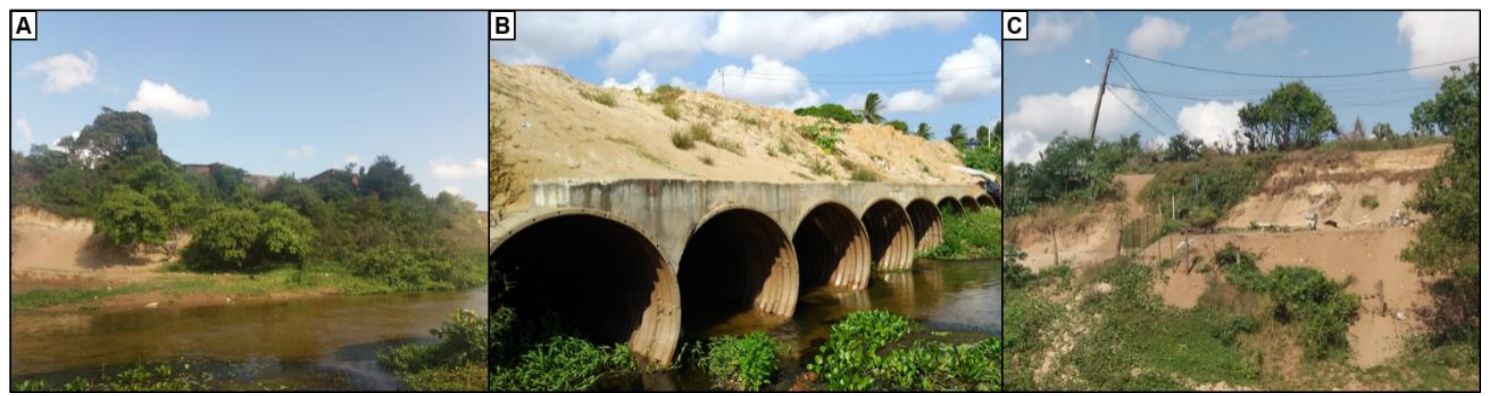

Fonte: arquivo pessoal dos autores.

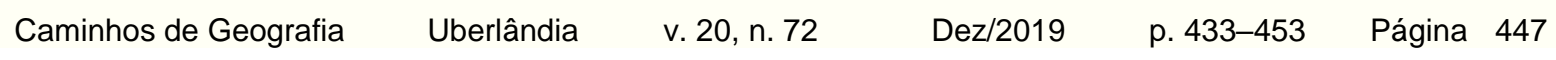


Figura 14 - Ocupação irregular sobre as dunas e a Lagoa Pluvial (A) e a pressão urbana sobre a área (B);

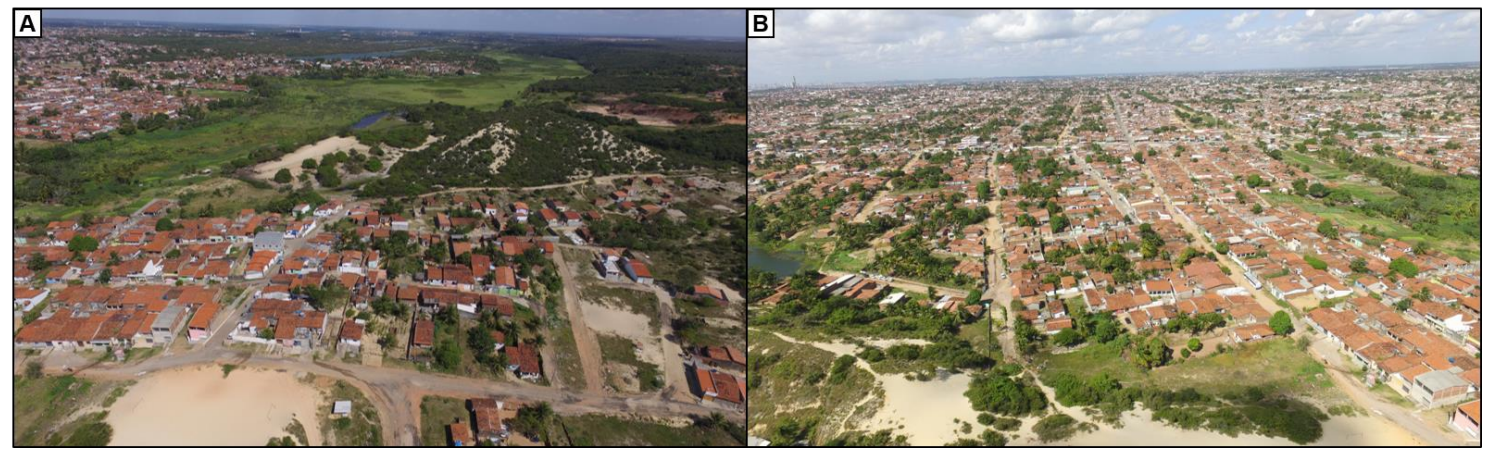

Fonte: Lutiane Almeida.

A forte pressão urbana e a impermeabilização do solo de áreas dunares e perímetros alagáveis de rios e lagoas tem como principal resultado, inundações e alagamentos. Transtornos estes constantes na área de estudo, e que são noticiados pelos jornais na cidade de Natal/RN, como pode ser constatado na figura 15, obtida do G1 RN do mês de julho de 2018, que é o período chuvoso na cidade, e do Agora RN no mês de novembro de 2017, que é período mais seco.

Figura 15 - Alagamento na Avenida Moema Tinoco) (A) e na Rua Tenente de Souza (B).

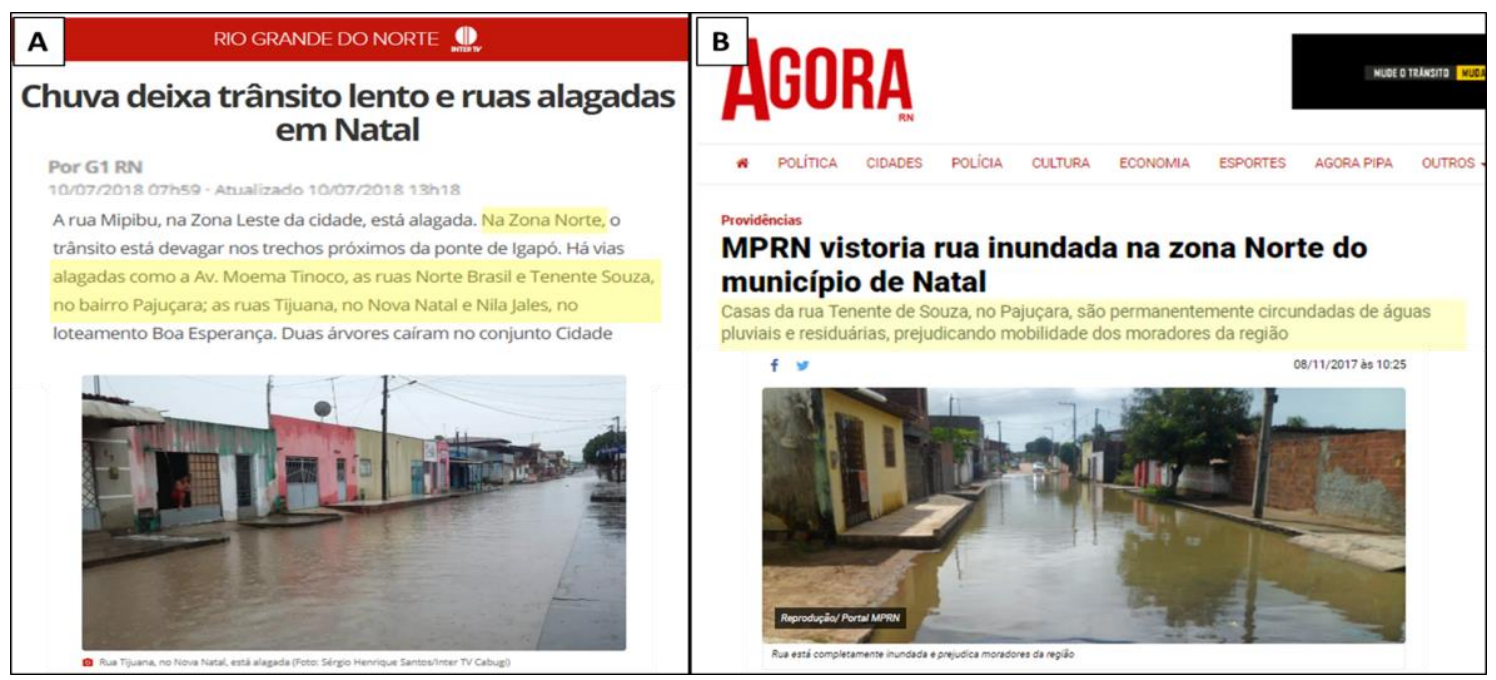

Fonte: G1 RN, 10 de julho de 2018 (A) e Agora RN, 08 de novembro de 2017 (B).

Além dos grandes transtornos urbanos, algumas das áreas em amarelo-vermelho no mapa da figura onze, correspondem aos campos de cultivo agrícola, os quais além de apresentarem uma média de vulnerabilidade 3,0, correspondem a áreas de adensamento urbano e solo frágil, que como pode ser observado nas figuras 16 e 17, ocorrem ao longo da ZPA e do Rio Doce: 
Figura 16 - Plantação de coqueiro sobre duna (A) e plantação de herbáceas (B).

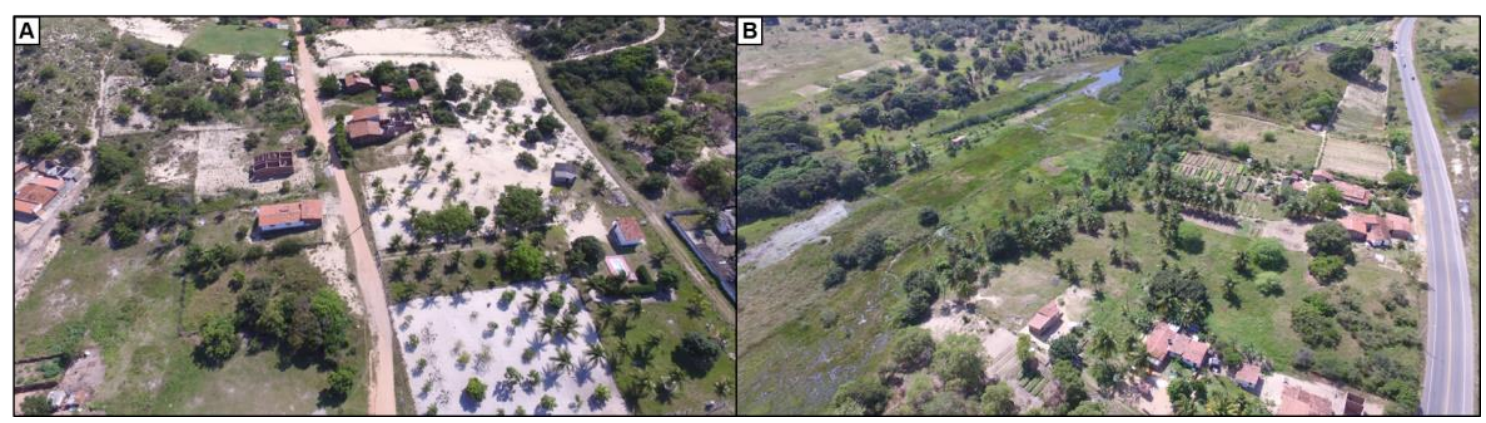

Fonte: Lutiane Almeida.

Figura 17 - Plantação de Herbáceas (A e C) e plantação de Banana (B).

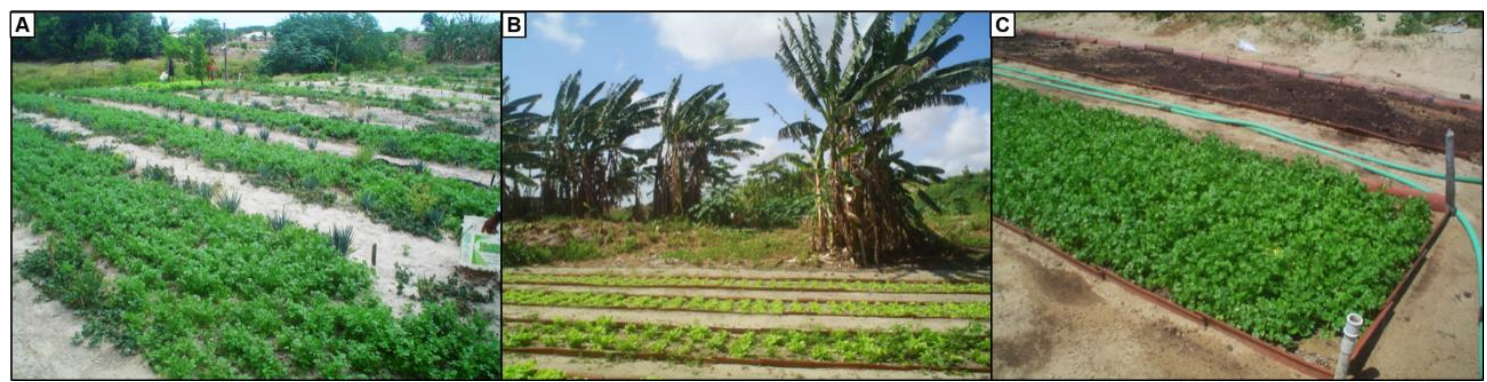

Fonte: arquivo pessoal dos autores.

As áreas em progressão verde no mapa que são as que possuem certo destaque correspondem as médias de vulnerabilidade que variam entre 1,8 e 2,2 (medianamente vulnerável). Nestas áreas onde o relevo é plano-ondulado, estão localizadas as maiores lagoas da ZPA 9, estes corpos hídricos e sua região adjacente embora apresentem média três no PI de Uso e Cobertura do solo, quando sobreposto aos demais PIs, a média de vulnerabilidade varia de 2,0 a 2,2 (medianamente vulnerável), o que pode ser explicado pela vegetação de restinga arbustiva, pela baixa declividade e altimetria, e pela ocupação urbana não adensada, conforme observado na figura 18.

Figura 18 - Relevo semiplano com baixa ocupação residencial (A) e Lagoas interdunares com predominância de restinga arbustiva (B).

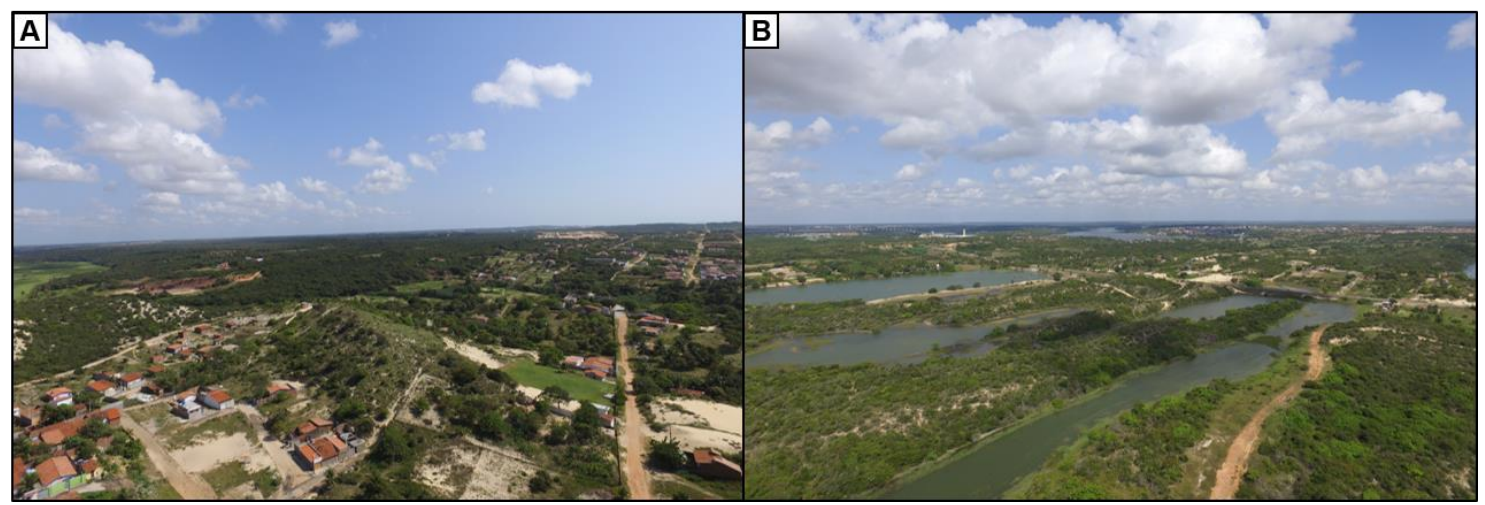

Fonte: Lutiane Almeida. 
Embora o grau de vulnerabilidade da maior parte das lagoas seja de 2,0 a 2,2 (medianamente vulnerável), vale salientar que estes corpos hídricos já apresentam processo de eutrofização, que é a produção superficial de algas devido à grande quantidade de matéria orgânica, proveniente de atividades agroagrícolas ou de esgotos domésticos, o que indica que há um processo ocupação urbana ainda irregular em curso, conforme a figura 19.

Figura 19 - Processo de eutrofização da Lagoa do Sapo (A) e da lagoa pluvial de Pajuçara (B).

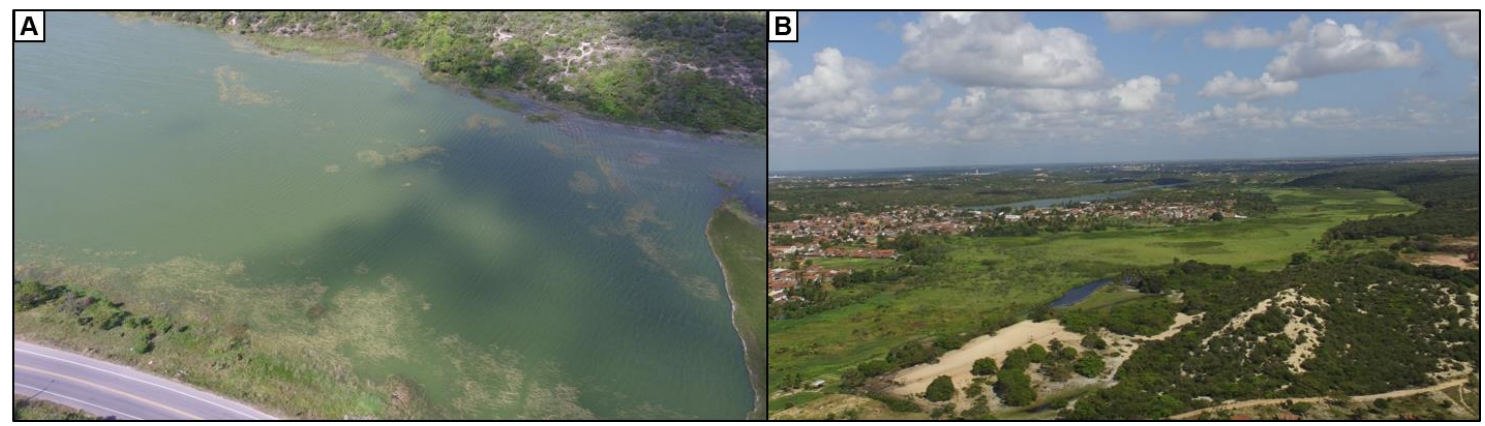

Fonte: Lutiane Almeida.

O Rio Doce, nas suas áreas próximas a BR-101, onde a ocupação urbana é rarefeita, o relevo é plano e há bastante vegetação, a média de vulnerabilidade varia de 1,8 a 2,1 (medianamente estável). Seguindo seu curso para Leste, a ocupação urbana é mais intensa, há a presença de encostas desnudas e cultivo de hortaliças, o grau de vulnerabilidade é de 2,5 (moderamente vulnerável), como observa na figura 20.

Figura 20 - Contenção da duna após corte de estrada (A) e assoreamento dunar natural do Rio Doce (B).

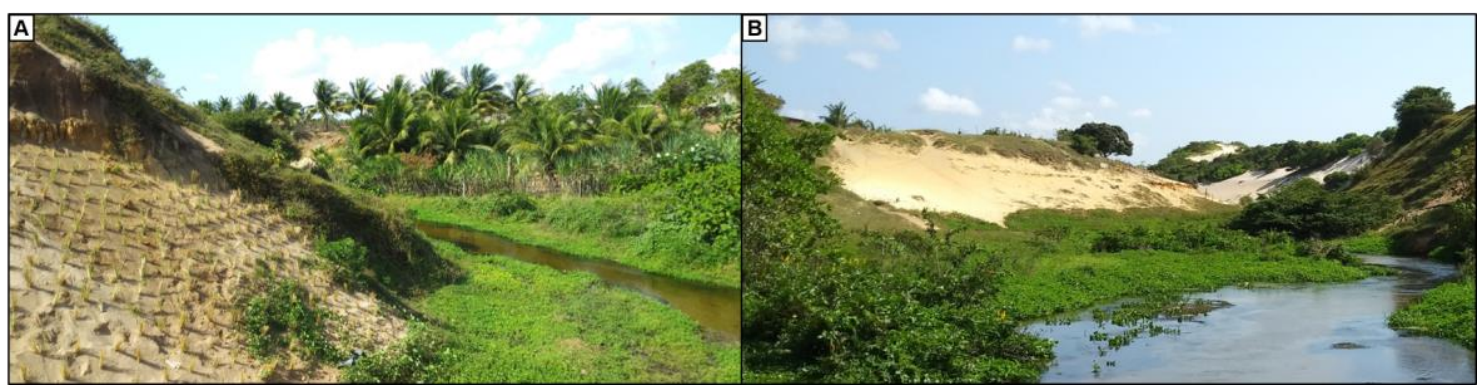

Fonte: arquivo pessoal dos autores.

O avanço urbano irregular sobre o Rio Doce, a produção agrícola com uso de agrotóxicos, a construção de rodovias e a ausência de um plano de gestão, são responsáveis pelos constantes transtornos urbanos e é claro pelo aumento da poluição hídrica e do lençol freático, fatos estes que também são noticiados como pode ser observado nas notícias da figura 21.

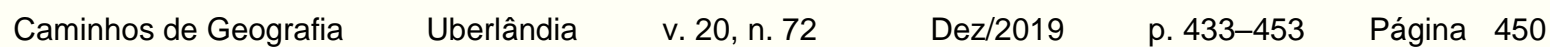


Figura 21 - Notícia sobre desabamento de ponte sobre o Rio Doce (A) e constante poluição dele (B).

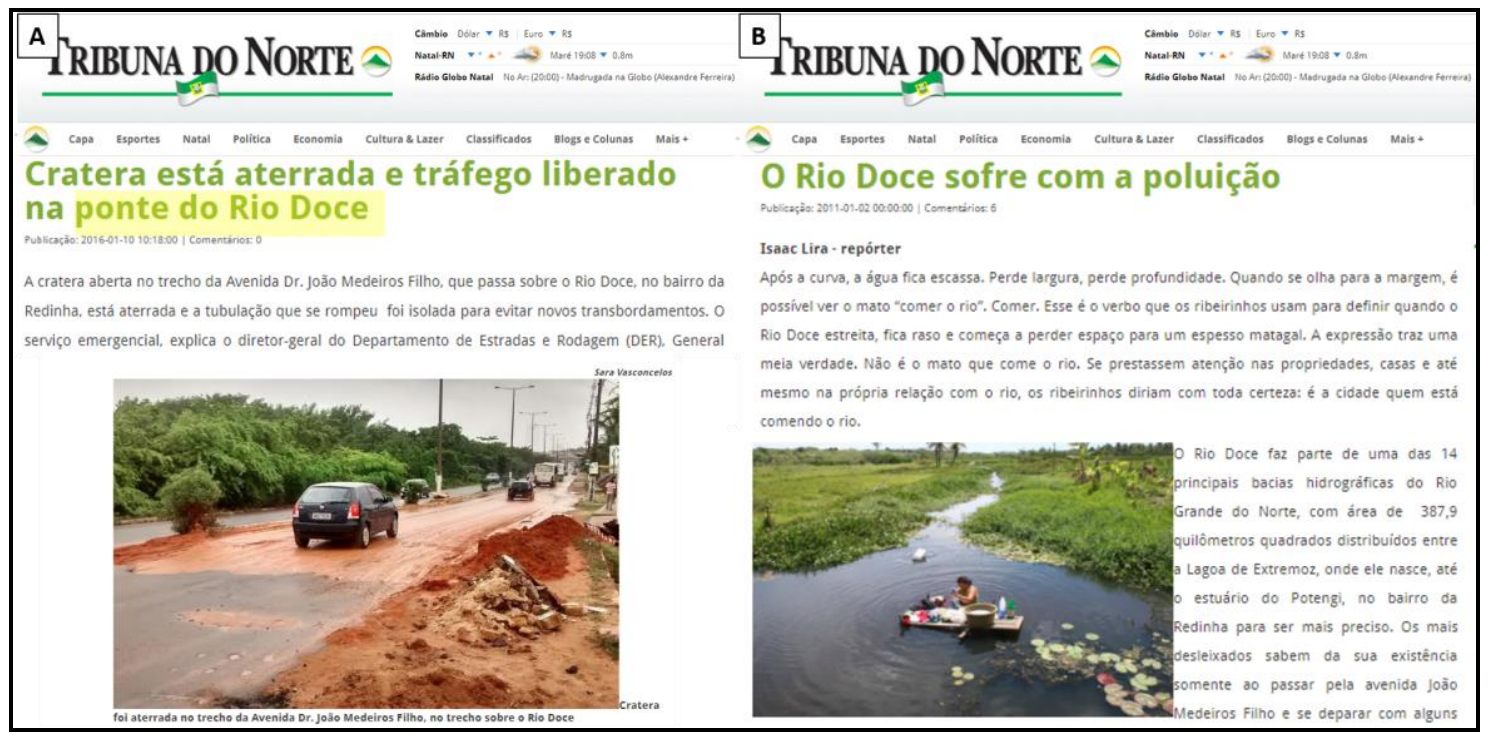

Fonte: Tribuna do Norte, 01 de outubro de 2016 (A) e Tribuna do Norte, 01 de fevereiro de 2011 (B).

Infelizmente a falta de planejamento urbano e a ocupação de áreas ambientalmente estáveis pela população da Zona Norte nas áreas adjacentes a ZPA 9, além de deixá-los expostos aos mais diversos tipos de riscos, contribui para a degradação de unidades ambientais e naturalmente vulneráveis, aumentando a susceptibilidade desta população a ocorrência de desastres, que variam desde inundações e alagamento à deslizamentos de terra.

Embora a pesquisa tenha enfatizado nos meios de identificação e na própria análise da vulnerabilidade ambiental da ZPA 9, compreender o arranjo espacial e o contexto socioeconômico em que a população está inserida é de suma importância para compreender em que medida a vulnerabilidade ambiental se inter-relaciona com os outros tipos de vulnerabilidade, e de como essa relação pode fornecer informações a respeito dos níveis de susceptibilidade, exposição e adaptação, não só como forma de preservar o meio ambiente, como também proporcionar melhores condições de vida a populações marginalizadas.

\section{CONSIDERAÇÕES FINAIS}

A sociedade atual é cerceada de riscos, populações socialmente marginalizadas pelo sistema, são submetidas a uma série de perigos, transtornos e desastres eminentes. Neste sentido, o desenvolvimento de estudos que analisem, instiguem e pesquisem o cerne do risco na geografia ou não, é de suma importância para evitar desastres e preservar a vida humana.

A metodologia utilizada apresentou algumas limitações e dificuldades, principalmente no que se refere às adaptações para o recorte espacial escolhido $E$ embora o questionamento de não ter sido feito um recorte espacial maior, como por exemplo, a Zona Norte, seja comum, o diferencial da área escolhida é que a ZPA 9 não é regulamentada, desta forma, identificar o grau de vulnerabilidade da mesma reforça a necessidade de criação de uma legislação pertinente, e isto a metodologia permitiu fazer.

Constituída por corpos hídricos e unidades ambientais naturais de beleza paisagística naturalmente vulneráveis, a ZPA 9 conta ainda com um alto processo de urbanização irregular que acarreta processos de degradação ambiental, decorrentesda carência de infraestrutura de saneamento e drenagem, com evidentes processos de erosão, contaminação e assoreamento dos cursos d'água, além dos riscos de alagamentos e deslizamentos.

Dessa forma verifica-se a necessidade urgente de regulamentação da ZPA 9, como também da elaboração e aplicação de um plano de gestão ao Rio Doce. Tendo por base esta e outras pesquisas, as medidas a serem tomadas devem ser no sentido de um planejamento e ordenamento urbano-

\begin{tabular}{llllll}
\hline Caminhos de Geografia & Uberlândia & v. 20, n. 72 & Dez/2019 & p. 433-453 & Página 451
\end{tabular}


ambiental, que contemple a recuperação, preservação e proteção ambiental da ZPA 9 e do rio doce, uma vez que o equilíbrio ambiental proporciona benefícios a saúde e ao bem-estar social, resultado que se dá através de políticas públicas eficientes.

\section{REFERÊNCIAS}

ALMEIDA, Lutiane Queiroz de. Riscos ambientais e vulnerabilidades nas cidades brasileiras: conceitos, metodologias e aplicações. São Paulo: Cultura Acadêmica, 2012. 214 p.

AZEVEDO, P. G. Vulnerabilidades Socioambientais na Zona de Proteção Ambiental - 9. Dissertação de Mestrado - UFRN, Curso de Geografia, Natal - RN, 2010.

BENTES SOBRINHA, Maria Dulce Picanço. A questão ambiental na legislação sobre uso e ocupação do solo em Natal: o entorno do Parque das Dunas. 1993. Dissertação (Mestrado) Universidade Federal do Rio Grande do Sul, Porto Alegre, 1993.

BRASIL. Congresso Nacional. Lei Federal no 10.257, de 10 de julho de 2001. Regulamenta os artigos 182 e 183 da Constituição Federal, estabelece as diretrizes gerais da Política Urbana e dá outras providências. Brasília, 2001.

CASTRO, M.; PEIXOTO, M. N. O.; PIRES DO RIO, G. A. Riscos ambientais e geografia: conceituações, abordagens e escalas. Anuário do Instituto de Geociências, Rio de Janeiro: UFRJ, v.28, n.2, p.11-30, 2005

CHUVA deixa trânsito lento e ruas alagadas em Natal. G1 RN. Natal, 10 jul. 2018. Disponível em: $<$ https://g1.globo.com/rn/rio-grande-do-norte/noticia/chuva-deixa-transito-lento-e-ruas-alagadas-emnatal.ghtml>. Acesso em: 04 ago. 2018

CPRM - Serviço Geológico do Brasil. Folha Natal SB-25-V-C-V. Recife: CPRM, 2012. Escala: 1:100.000. Disponível em: <http://www.cprm.gov.br>. Acesso em: 27 ago. 2019.

CRATERA está aterrada e tráfego liberado na ponte do Rio Doce. Tribuna do Norte. Natal, 10 jan. 2016. Disponível em: <http://www.tribunadonorte.com.br/noticia/cratera-esta-aterrada-e-tra-fegoliberado-na-ponte-do-rio-doce/335229>. Acesso em: 04 ago. 2018.

CREPANI, E. et al,.Sensoriamento Remoto e Geoprocessamento Aplicados ao Zoneamento Ecológico-Econômico e ao Ordenamento Territorial. São José dos Campos, INPE, 2001.

DUARTE, Marise Costa de Souza. Espaços especiais urbanos: desafios à efetivação dos direitos ao meio ambiente e à moradia. Rio de Janeiro: Letra capital, 2011. 526 p.

EMBRAPA. Centro Nacional de Pesquisa de Solos. Sistema brasileiro de classificação de solos. 2. ed. Rio de Janeiro, 2006. 306 p.

ESTEVES, Cláudio Jesus de Oliveira. Risco e Vulnerabilidade Socioambiental: Aspectos Conceituais. Caderno Ipardes, Curitiba, v. 1, p.62-79, jul./dez. 2011.

GIDDENS, Anthony. As consequências da Modernidade. São Paulo: Editora Unesp, 1991. 156 p.

IDEMA - Instituto de Desenvolvimento Sustentável e Meio Ambiente do Rio Grande Do Norte. Natal: divisão municipal. Arquivos Shapefiles, 2016. CD-ROM.

JONES, D. Environmental hazards in the 1990s: problems, paradigms and prospects. Geography, v.78, n.2, p.161-165, 1993.

LIRA, Isaac. O rio doce sofre com a poluição. Tribuna do Norte. Natal, p. 1-1. 01 fev. 2011. Disponível em: <http://www.tribunadonorte.com.br/noticia/o-rio-doce-sofre-com-apoluicao/169124>. Acesso em: 04 ago. 2018.

MARANDOLA JR., Eduardo; HOGAN, Daniel Josehp. Natural Harzards: o estudo geográfico dos perigos. Revista Ambiente e Sociedade, Campinas, v. 7, n. 2, p.95-109, jul./ dez, 2004.

https://doi.org/10.1590/S1414-753X2004000200006

. As dimensões da Vulnerabilidade. São Paulo em Perspectiva, São Paulo, v. 20, p.33-43, jan./mar. 2006.

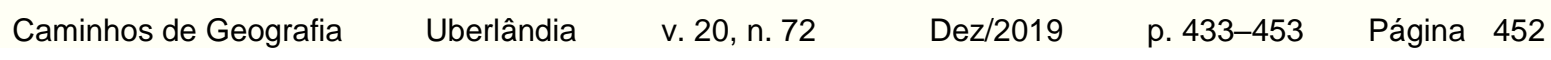


MEDEIROS, Marysol Dantas de. Vulnerabilidade Socioambiental no Município de Natal/RN. 2014. 167 f. Dissertação (Mestrado) - Curso de Geografia, Universidade Federal do Rio Grande do Norte, Natal, 2014.

MPRN vistoria rua inundada na zona Norte do município de Natal. Agora RN. Natal, 08 nov. 2017. Disponível em: <https://agorarn.com.br/cidades/mprn-vistoria-rua-inundada-na-zona-norte-domunicipio-de-natal/>. Acesso em: 04 ago. 2018

NATAL (Município). SEMURB - Secretaria Municipal de Meio Ambiente e Urbanismo. ACQUATOOL CONSULTORIA. (org.). Plano Municipal de Redução de Risco do Município de Natal. Natal: SEMURB, 2008. 3 v.

NATAL (Município). SEMURB - Secretaria Municipal de Meio Ambiente e Urbanismo. Natal: Divisão municipal de bairros e Zonas de Proteção Ambiental. Arquivos Shapefiles, 2016. CD-ROM.

NATAL. Câmara Municipal. Lei n².211, de 10 de julho de 1974. Plano Diretor do Município. Natal, 1974.

Lei $\mathbf{n}^{\circ}$ 3.175, de 26 de janeiro de 1984. Dispõe sobre o Plano Diretor de Organização Físico-Territorial do Município e dá outras providências. Natal, 1984.

Lei complementar $n^{\circ} \mathbf{2 . 2 1 1}$, de 5 de agosto de 1994. Dispõe sobre o Plano Diretor de Natal e dá outas providências. Natal, 1994.

. Lei Complementar no 082, de 21 de junho de 2007. Dispõe sobre o Plano Diretor de Natal e dá outras providências. Natal, 2007.

PRODETUR - Programa Regional de Desenvolvimento do Turismo. Natal: Topografia. Arquivos Shapefiles, 2013. CD-ROM.

. Imagens de Satélite. Natal: Mosaico de imagens, 2013. Escala 1:10.000. CD-ROM.

SMITH, K. Environmental hazards: assessing risk and reducing disaster. 3 ed. 392p. Londres: Routledge, 2001.

VEYRET, Y. Os riscos: O homem com agressor e vítima do meio ambiente: São Paulo: Contexto, 2007.

WHITE, G. F., KATES, R. K., BURTON, I. Knowing better ans losing even more: the use of knowledge in hazards management. Environmental Hazards, v. 3, n. 3-4, p. 81-92, 2001. 77.

https://doi.org/10.1016/S1464-2867(01)00021-3 